\title{
A Cross Talk between Neuronal Urokinase-type Plasminogen Activator (uPA) and Astrocytic uPA Receptor (uPAR) Promotes Astrocytic Activation and Synaptic Recovery in the Ischemic Brain
}

\author{
(DAriel Diaz, ${ }^{1,2}$ Paola Merino, ${ }^{1,2}$ - Luis Guillermo Manrique, ${ }^{1,2}$ - Juan Pablo Ospina, ${ }^{1,2}$ Lihong Cheng, ${ }^{1,2}$ Fang Wu, ${ }^{1,2}$ \\ Valerie Jeanneret, ${ }^{1,2}$ and (DManuel Yepes ${ }^{1,2,3}$ \\ ${ }^{1}$ Department of Neurology and Center for Neurodegenerative Disease, Emory University School of Medicine, Atlanta, Georgia 30322, ${ }^{2}$ Division of \\ Neuropharmacolgy and Neurologic Diseases, Yerkes National Primate Research Center, Atlanta, Georgia 30329, and ${ }^{3}$ Department of Neurology, Veterans \\ Affairs Medical Center, Atlanta, Georgia 30033
}

Urokinase-type plasminogen activator (uPA) is a serine proteinase that, upon binding to its receptor (uPAR), catalyzes the conversion of plasminogen into plasmin on the cell surface. Our previous studies indicate that uPA and uPAR expression increase in the ischemic brain during the recovery phase from an acute ischemic injury and that uPA binding to uPAR promotes neurological recovery after an acute ischemic stroke. Here, we used male mice genetically deficient on either $\mathrm{uPA}\left(\mathrm{uPA}^{-1-}\right)$ or $\mathrm{uPAR}\left(\mathrm{uPAR}^{-1-}\right)$ or with a four-amino acid substitution into the growth factor domain of uPA that abrogates its binding to uPAR (Plat $\left.{ }^{\mathrm{GFDhu} / \mathrm{GFDhu}}\right)$ to investigate the mechanism whereby uPA promotes neurorepair in the ischemic brain. We found that neurons release UPA and astrocytes recruit uPAR to their plasma membrane during the recovery phase from a hypoxic injury and that binding of neuronal uPA to astrocytic uPAR induces astrocytic activation by a mechanism that does not require plasmin generation, but instead is mediated by extracellular signal-regulated kinase 1/2 (ERK1/2)regulated phosphorylation of the signal transducer and activator of transcription 3 (STAT3). We report that uPA/uPAR binding is necessary and sufficient to induce astrocytic activation in the ischemic brain and that astrocytes activated by neuronal uPA promote synaptic recovery in neurons that have suffered an acute hypoxic injury via a mechanism mediated by astrocytic thrombospondin-1 (TSP1) and synapticlow-density lipoprotein receptor-related protein-1 (LRP1). In summary, we show that uPA/uPAR-induced astrocytic activation mediates a cross talk between astrocytes and injured neurons that promotes synaptic recovery in the ischemic brain.

Key words: astrogliosis; neurorepair; plasmin; recovery; urokinase-type plasminogen activator

Significance Statement

To date, there is no therapeutic strategy to promote synaptic recovery in the injured brain. Here, we show that neurons release urokinasetype plasminogen activator ( $\mathrm{uPA}$ ) and astrocytes recruit the $\mathrm{uPA}$ receptor ( $\mathrm{UPAR})$ to their plasma membrane during the recovery phase from a hypoxic injury. We found that binding of neuronal uPA to astrocytic uPAR promotes astrocytic activation and that astrocytes activated by uPA- uPAR binding promote synaptic recovery in neurons that have suffered a hypoxic injury by a mechanism that does not require plasmin generation, but instead is mediated by ERK1/2-regulated STAT3 phosphorylation, astrocytic thrombospondin-1 (TSP1) and synaptic low-density lipoprotein receptor-related protein-1 (LRP1). Our work unveils a new biological function for uPA- uPAR as mediator of a neuron-astrocyte cross talk that promotes synaptic recovery in the ischemic brain.

\section{Introduction}

The intimate contact between neurons and astrocytes in the CNS (Oberheim et al., 2012) has led to the use of the term "tripartite synapse" (Perea et al., 2009) to conceptualize the fact that astrocytes can regulate synaptic function in response to changes in the neuronal microenvironment (Bernardinelli et al., 2014). Accordingly, astrocytes can sense variations in synaptic activity (Panatier 
et al., 2011) and, in response to this information, induce synaptic plasticity (Jourdain et al., 2007) and either the elimination (Chung et al., 2013) or formation and stabilization (Ullian et al., 2001; Slezak and Pfrieger, 2003; Hama et al., 2004; Nishida and Okabe, 2007) of new synapses.

Astrocytic activation is an evolutionarily preserved process whereby, in response to a variety of stimuli, astrocytes develop cellular hypertrophy and filopodia formation alongside well defined genetic and biochemical changes (Wang et al., 2012). Cerebral ischemia is an effective inductor of astrocytic activation (Pekny and Pekna, 2014). However, the role of activated astrocytes in the ischemic brain is still unclear. Therefore, whereas some have proposed that they have a protective effect (Li et al., 2008), others have reported a deleterious role by preventing the integration of newly formed neuronal circuits during the recovery phase from the ischemic injury (Silver and Miller, 2004).

Urokinase-type plasminogen activator ( $\mathrm{UPA}$ ) is a serine proteinase that, upon binding to its receptor (UPAR), is cleaved by plasmin to generate an active form that catalyzes the conversion of plasminogen into plasmin (Lijnen et al., 1987). During CNS development, uPA and uPAR are found abundantly in neurons and in a subpopulation of oligondendrocytes (Sumi et al., 1992; Dent et al., 1993). In contrast, in the adult brain, uPAR expression is limited to the distal segment of some growth cones and dendrites (Merino et al., 2017). Interestingly, during the recovery phase from an ischemic injur,y the concentration of uPA increases in ischemic tissue (Wu et al., 2014) and uPAR gene expression is induced in activated astrocytes (Zamanian et al., 2012). The functional relevance of these findings is underscored by the observation that binding of either recombinant or endogenous uPA to uPAR improves neurological outcome in experimental models of ischemic stroke (Wu et al., 2014; Merino et al., 2017).

Thrombospondins (TSPs) are large extracellular proteins that mediate cell-matrix and cell-cell interactions (Adams and Lawler, 2011). There are five TSPs and it has been shown that two of them, TSP 1 and TSP2, are secreted by activated astrocytes and promote synaptogenesis by their interaction with an as yet unknown receptor (Christopherson et al., 2005). In addition, it has been shown that activation of the signal transducer and activator of transcription-3 (STAT3) preserves the integrity of the synapse and regulates the expression of astrocytic TSP 1 and the formation of filopodia in reactive astrocytes (Tyzack et al., 2014). The lowdensity lipoprotein receptor-related protein-1 (LRP1) is a member of the LDL receptor family assembled by a $515 \mathrm{kDa}$ heavy chain noncovalently bound to an $85 \mathrm{kDa}$ chain containing a transmembrane and a cytoplasmic domains (Herz and Strickland, 2001). LRP1 interacts with TSP1 (Resovi et al., 2014) and plays a pivotal role maintaining the integrity of the synapse (Liu et al., 2010; Nakajima et al., 2013).

In the work presented here, we show that, during the recovery phase from a hypoxic injury, neurons release uPA and astrocytes recruit uPAR to their plasma membrane. We report that binding of neuronal uPA to astrocytic UPAR induces astrocytic activation by a mechanism that does not require plasmin generation, but instead involves ERK1/2-mediated STAT3 activation. We found that $\mathrm{uPA} / \mathrm{uPAR}$-activated astrocytes promote synaptic recovery

Correspondence should be addressed to Manuel Yepes, Department of Neurology and Center for Neurodegenerative Disease, Emory University, Whitehead Biomedical Research Building, 615 Michael Street, Suite 505J, Atlanta, GA 30322.E-mail:myepes@emory.edu.

DOI:10.1523/JNEUROSCI.1630-17.2017

Copyright $\odot 2017$ the authors $\quad 0270-6474 / 17 / 3710311-13 \$ 15.00 / 0$ in neurons that have suffered a hypoxic injury by a mechanism mediated by astrocytic TSP 1 and synaptic LRP1. In summary, the results presented here unveil a novel role for UPA-uPAR binding in the CNS as a mediator of a neuron-astrocyte cross talk that promotes synaptic recovery in the ischemic brain.

\section{Materials and Methods}

Animals and reagents. Animal strains were 8- to 12-week-old C57BL/6J male uPA-deficient $\left(\mathrm{uPA}^{-1-}\right)$, uPAR-deficient $\left(\mathrm{uPAR}^{-1-}\right)$, and Plat ${ }^{\text {GFDhu/GFDhu }}$ mice (with a four-amino acid substitution into the growth factor domain of uPA that abrogates its binding to UPAR while preserving other functions of the protease and its receptor; Connolly et al., 2010) and their wild-type (WT) littermate controls (a generous gift from Dr. Thomas H. Bugge, Oral and Pharyngeal Cancer Branch, National Institute of Dental and Craniofacial Research, National Institutes of Health, Bethesda, MD). Experiments were approved by the Institutional Animal Care and Use Committee of Emory University, Atlanta, GA. Recombinant murine uPA (ruPA), uPA's $\mathrm{N}$ terminal fragment (ATF), and an ELISA kit to quantify uPA were purchased from Molecular Innovations. Other materials were the propidium iodide uptake kit (AnaSpec), the ERK1/2 inhibitor SL327 (Tocris Bioscience), and antibodies against rabbit GFAP (Dako), uPAR (R\&D Systems), bassoon (Abcam), PSD-95, STAT3 phosphorylated at Tyr 705 (pSTAT3) and ERK1/2 phosphorylated at Thr202/Tyr204 and total ERK1/2 (Cell Signaling Technology), TSP1 A6.1 monoclonal antibodies (Thermo Fisher Scientific), and $\beta$ actin (Sigma-Aldrich). The nuclear marker Hoechst 33342 was from Invitrogen and phalloidin was from Thermo Fisher Scientific. The receptor-associated protein (RAP) and monoclonal antibodies that recognize the intracellular domain of LRP1 were a kind gift from Dr. Dudley K. Strickland (University of Maryland, College Park, MD).

Astrocytic and neuronal cultures and determination of neuronal survival. $\mathrm{WT}$ and $\mathrm{uPAR}^{-1-}$ astrocytes and WT and $\mathrm{uPA}^{-1-}$ cerebral cortical neurons were cultured, as described previously, from 1-d-old and embryonic day 16 (E16)-E18 mice, respectively (Echeverry et al., 2010). Briefly, the cerebral cortex was dissected, transferred into Hank's balanced salt solution containing $100 \mathrm{units} / \mathrm{ml}$ penicillin, $100 \mu \mathrm{g} / \mathrm{ml}$ streptomycin, and $10 \mathrm{~mm}$ HEPES, and incubated in trypsin containing $0.02 \%$ DNase at $37^{\circ} \mathrm{C}$ for $15 \mathrm{~min}$. Tissue was triturated and the supernatant was resuspended in GS21-supplemented Neurobasal medium containing $2 \mathrm{~mm}$ L-glutamine and plated onto $0.1 \mathrm{mg} / \mathrm{ml}$ poly-L-lysine-coated wells. For astrocytes, the triturated tissue was resuspended in 10\% FBS DMEM and filtered through a $70 \mu \mathrm{m}$ pore membrane. Then cells were plated onto poly-L-lysine-coated T75 flasks. Ten to $14 \mathrm{~d}$ later, astrocytes were plated and used for experiments upon confluency 7-14 d thereafter. To quantify neuronal survival, WT neurons were kept under physiological conditions or exposed during $5 \mathrm{~min}$ to either oxygen and glucose deprivation (OGD: $<0.1 \%$ oxygen and no glucose) in an anaerobic chamber (Don Whitley Scientific) or $50 \mu \mathrm{m}$ glutamate. The uptake of propidium iodide was studied in each experimental group following the manufacturer's instructions. Images were taken at $40 \times$ magnification and propidium iodide-positive neurons per field were identified visually and counted with the ImageJ analysis system. Results are given as a percentage of propidium iodide-positive neurons after exposure to OGD in relation to the number of propidium iodide-positive neurons in cultures maintained under physiological conditions.

Preparation of synaptoneurosomes. Synapse-enriched fractions containing the presynaptic terminal and the attached postsynaptic membrane (synaptoneurosomes) were prepared according to a modification of published protocols (Rao and Steward, 1991; An et al., 2008; Weingarten et al., 2014; Wilhelm et al., 2014) from either neuron-astrocyte cocultures or the cerebral cortex of WT mice. Tissue was homogenized and centrifuged at $2000 \times g$ for $5 \mathrm{~min}$. Pellets were discarded and the supernatants centrifuged in an SS-20 fixed angle rotor at 32,000 $\times g$ for $10 \mathrm{~min}$ to obtain pellet 2 . Pellets were resuspended and layered on top of a $5 \%$, 9\%, and 13\% discontinuous Ficoll (Thermo Fisher Scientific) gradient and centrifuged at $45,000 \times g$ for $20 \mathrm{~min}$ at $4^{\circ} \mathrm{C}$ in a TLS 55 rotor using a Beckman Optima TLX tabletop ultracentrifuge. Synaptoneurosomes were collected from the 5\%/9\% and 9\%/13\% interfaces. 
Animal model of cerebral ischemia. Transient occlusion of the middle cerebral artery (tMCAO) was induced in WT, $\mathrm{uPA}^{-1-}, \mathrm{uPAR}^{-1-}$, and Plat ${ }^{\text {GFDhu/GFDhu }}$ mice with a $6-0$ silk suture advanced from the external carotid artery (ECA) into the internal carotid artery until the origin of the middle cerebral artery (MCA) as described previously (Wu et al., 2012). Briefly, a nylon monofilament (6-0; Ethicon) coated with silicone was introduced through the ECA and advanced to the origin of the MCA. The suture was withdrawn after $30 \mathrm{~min}$ of cerebral ischemia. Cerebral perfusion (CP) in the distribution of the MCA was monitored before and throughout the surgical procedure and after reperfusion with a laser Doppler (Perimed) and only animals with a $>80 \%$ decrease in CP after occlusion and complete recovery after suture withdrawal were included in this study. The rectal and masseter muscle temperatures were controlled at $37^{\circ} \mathrm{C}$ with a homoeothermic blanket. Blood pressure was monitored throughout the surgical procedure with an IITC 229 System and kept within the 120-125/70-75 mmHg range.

Western blot analysis. For the in vitro experiments, extracts were prepared from WT and uPAR $^{-1-}$ astrocytes kept under normoxic conditions or exposed to $1 \mathrm{~h}$ of OGD or incubated for $0-3 \mathrm{~h}$ with $5 \mathrm{nM} \mathrm{uPA}$ alone or in the presence of $10 \mu \mathrm{M}$ SL327 or from synaptoneurosomes prepared from either isolated neuronal cultures or from WT neurons maintained in the presence of WT astrocytes. For the in vivo experiments, extracts were prepared from the ipsilateral (ischemic) and contralateral (nonischemic) hemispheres of WT, $\mathrm{uPAR}^{-1-}$, and $\mathrm{uPA}^{-1-}$ mice $4 \mathrm{~d}$ after $30 \mathrm{~min}$ of tMCAO and intravenous treatment with $0.1 \mathrm{mg} / \mathrm{kg}$ ruPA or a comparable volume of saline solution, from the ischemic tissue of WT ant $\mathrm{uPAR}^{-1-}$ mice immediately after $30 \mathrm{~min}$ of $\mathrm{tMCAO}$, or from synaptoneurosomes isolated from the cerebral cortex of WT mice under nonischemic conditions. Protein concentration was quantified in the astrocytic and brain extracts using the BCA assay and $15 \mu \mathrm{g}$ of protein were loaded per sample, separated in a $4-20 \%$ precast linear gradient polyacrylamide gel (Bio-Rad), transferred to a PVDF membrane by semidry transfer system, blocked with $5 \%$ nonfat dry milk in Trisbuffered saline, $\mathrm{pH} 8.0$, with $0.1 \%$ Tween 20 buffer, and immunoblotted with an antibodies against GFAP (1:40000), uPAR (1:1000), actin (1: $50000)$, pERK 1/2 (1:2000), and total ERK 1/2 (1:1000), PSD-95 (1;1000), synaptophysin (1:1000), the intracellular domain of LRP1 (1:1000), and TSP1 (1:1000). Membranes were developed in a Kodak M35A X-OMAT processor, films were scanned, and densitometry analysis was performed in each band using the UN-SCAN-IT gel software (version 6.1). All values were normalized to actin with exception of phosphorylated ERK1/2, which was normalized to total ERK1/2. Data were further normalized to their own controls or to values obtained in nonischemic samples (for the in vivo experiments). Each experiment was repeated at least three to four times as indicated in the corresponding figure legend.

Cell surface biotinylation assay. The biotinylation assay was performed as described previously (Merino et al., 2017). Briefly, WT astrocytes exposed to $60 \mathrm{~min}$ of OGD conditions or maintained under normoxia were washed, incubated with biotin solution (Sulfo-NHS-SS-Biotin), and centrifuged at $500 \times g$ for $3 \mathrm{~min}$. Pellets were resuspended in $5 \mathrm{ml}$ of TBS, centrifuged at $500 \times g$ for $3 \mathrm{~min}$, lysed, sonicated on ice, and centrifuged at $10,000 \times g$ for $2 \mathrm{~min}$ at $4^{\circ} \mathrm{C}$. The supernatant was added to the gel in columns previously prepared with NeutrAvidin agarose, washed three times, and centrifuged for $1 \mathrm{~min}$ at $1000 \times \mathrm{g}$. Then, $400 \mu \mathrm{l}$ of dithiothreitolcontaining sample buffer was added to the columns, centrifuged for $2 \mathrm{~min}$ at $1000 \times g$, and immunoblotted with anti-uPAR antibodies. Quantification of the density of each band was performed as described above.

Immunochemistry. To study the effect of hypoxia and uPA on astrocytic activation and STAT3 phosphorylation in vitro, WT astrocytes were kept under normoxic conditions, exposed to $1 \mathrm{~h}$ of OGD conditions, or incubated for $1 \mathrm{~h}$ with $5 \mathrm{~nm}$ uPA alone or in the presence of $10 \mu \mathrm{M}$ SL327. Cells were fixed with $100 \%$ methanol for $10 \mathrm{~min}$ at $-20^{\circ} \mathrm{C}$, washed 3 times in TBS, and incubated for $30 \mathrm{~min}$ in a blocking solution containing $1 \mathrm{ml}$ of $0.2 \mathrm{~mm}$ glycine, $20 \mu \mathrm{l} / \mathrm{ml}$ casein, and $5 \mu \mathrm{l} / \mathrm{ml}$ donkey serum. Then samples were kept overnight on a solution containing anti-GFAP (1: $2000)$ and either anti-uPAR (1:100) or anti-pSTAT3 antibodies (1:100). Secondary antibodies were anti-goat Alexa Fluor 488 (1:500) and antirabbit Alexa Fluor 594 (1:500). Phalloidin (1:1000) and Hoechst (1: $10,000)$ were added for $20 \mathrm{~min}$. Images were taken in an Olympus microscope BX51 with a $40 \times$ and $100 \times$ magnification for cell and filopodia quantification, respectively. Counts were performed manually with Image software.

To study the effect of cerebral ischemia on astrocytic activation and STAT3 phosphorylation WT, $\mathrm{uPAR}^{-1-}$ and $\mathrm{uPA}^{-1-}$ mice underwent 30 min of tMCAO. A subgroup of WT, $\mathrm{uPAR}^{-1-}$, and $\mathrm{uPA}^{-1-}$ animals were treated intravenously immediately after tMCAO with either $0.1 \mathrm{mg} / \mathrm{kg}$ ruPA or a comparable volume of saline solution. To study astrocytic activation and STAT3 phosphorylation, brains were harvested 4 or $2 \mathrm{~d}$ later, respectively. In each case, $20 \mu \mathrm{m}$ brains sections were incubated with $0.5 \%$ Triton X-100 for $30 \mathrm{~min}$, washed, and blocked using 3\% BSA in TBS, immunoreacted overnight with anti-GFAP (1:2000) antibodies alone or in combination with anti-pSTAT antibodies (1:500), washed with TBS, and incubated with secondary anti-mouse Alexa Fluor 488 (1:500) and anti-rabbit Alexa 594 (1:500) antibodies for $1 \mathrm{~h}$ at room temperature and Hoechst $(1: 10,000)$ for $10 \mathrm{~min}$. To quantify the percentage of GFAP- and pSTAT3-positive astrocytes in the ischemic tissue, images were taken with identical exposures times for each section with an Olympus microscope BX51 at bregma $-0.34 \mathrm{~mm}$ (Paxinos and Franklin, 2001). Then, the number of GFAP-positive and GFAP-negative Hoechstpositive cells and GFAP-immunoreactive cells positive for PSTAT3 were quantified manually in the ischemic area at a $40 \times$ magnification with the Image software.

To study the effect of the intrastriatal injection of uPA on astrocytic activation and STAT3 phosphorylation, WT and $\mathrm{UPAR}^{-1-}$ mice were placed on a stereotactic frame, a burr hole was opened, and $0.5 \mu \mathrm{l}$ of a $5 \mathrm{~nm}$ solution of either murine uPA or ATF or a comparable volume of PBS was injected for $20 \mathrm{~min}$ at bregma: $0.02 \mathrm{~mm}$; lateral: $2.5 \mathrm{~mm}$; and ventral: $3.5 \mathrm{~mm}$ (Paxinos and Franklin, 2001). Before the intrastriatal injections, a subgroup of WT mice was injected into their third ventricle with $2 \mu$ l of a $2.2 \mathrm{~mm}$ solution of SL327 or a comparable volume of PBS at bregma: $-0.94 \mathrm{~mm}$; lateral: $0 \mathrm{~mm}$; ventral: $2.5 \mathrm{~mm}$ (Paxinos and Franklin, 2001). Forty-eight hours later, $30 \mu \mathrm{m}$ sections were cut through the striatum, fixed and treated as described above, and incubated with antiGFAP antibodies (1:2000) alone or in combination with anti-pSTAT3 antibodies (1:100). Secondary antibodies were donkey anti-rabbit Alexa Fluor 488 (1:500) and donkey anti-mouse Alexa Fluor 594 (1:500). To determine the number of astrocytes immunoreactive to either GFAP or pSTAT3 antibodies in the striatum, images were taken at $40 \times$ magnification and the number of Hoechst-positive GFAP-positive and -negative cells and GFAP-positive pSTAT3-immunoreactive cells were determined manually with ImageJ. To determine the area of the striatum immunoreactive to GFAP after uPA treatment, images were taken at $4 \times$ magnification throughout the striatum and stitched with Adobe Photoshop. The area immunoreactive to GFAP was then quantified with ImageJ.

To study the effect of endogenous uPA binding to uPAR on synaptic recovery in vitro, coverslips with $16-18 \mathrm{~d}$ in vitro $\mathrm{WT}$ or $\mathrm{uPA}^{-1-}$ neurons were maintained under normoxic conditions alone or in the presence of WT astrocytes or exposed to $5 \mathrm{~min}$ of OGD conditions and then transferred to wells containing WT or $\mathrm{uPAR}^{-1-}$ astrocytes either previously exposed to $3 \mathrm{~h}$ of OGD (to induce their activation) or maintained under normoxic conditions. A subgroup of cocultures was incubated during the recovery phase with either $4 \mu \mathrm{g} / \mathrm{ml}$ anti-TSP1 antibodies or an IgG isotype control or with $125 \mathrm{~nm}$ RAP. Twenty-four hours later, neuronal cultures or neuron-astrocyte cocultures were fixed and incubated with antibodies against PSD-95 (1:200) and bassoon (1:2000). Images were taken at $60 \times$ magnification and the number of puncta immunoreactive to PSD-95 and bassoon in 50- $\mu$ m-length extensions was determined manually with Image J.

To study the effect of endogenous uPA-uPAR binding on synaptic recovery in vivo, WT and Plau GFDhu/GFDhu mice underwent $30 \mathrm{~min}$ of tMCAO or sham operation. Brains were harvested immediately after tMCAO or following $4 \mathrm{~d}$ of reperfusion after 30 min of tMCAO (recovery), cut into $20 \mu \mathrm{m}$ sections, processed as described above, immunoreacted overnight with antibodies against PSD-95 (1:100) and bassoon (1:1000), and incubated with secondary anti-mouse Alexa Fluor 488 (1: $500)$ and anti-rabbit Alexa 594 (1:500) antibodies for $1 \mathrm{~h}$ and Hoechst (1:10000) for $10 \mathrm{~min}$. Images were taken with a Fluoview FV10i confocal 
A
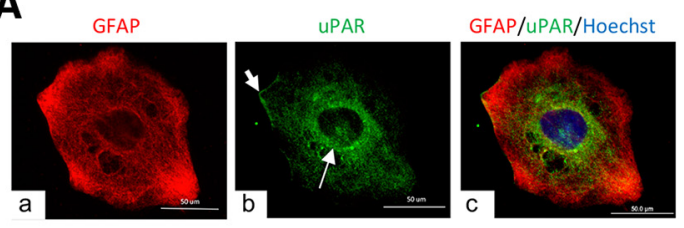

B

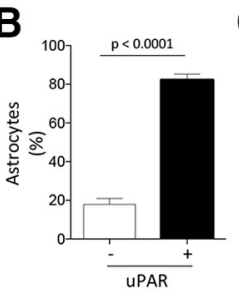

$\mathbf{F}$

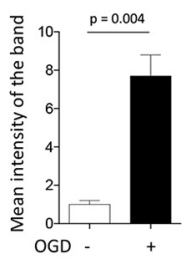

G

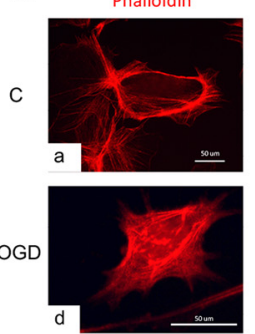

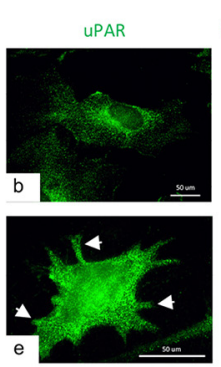

C

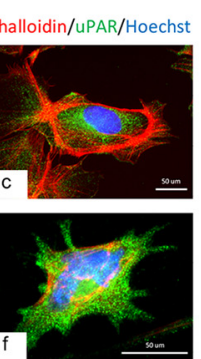

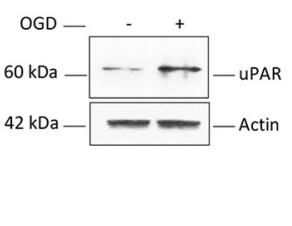

H

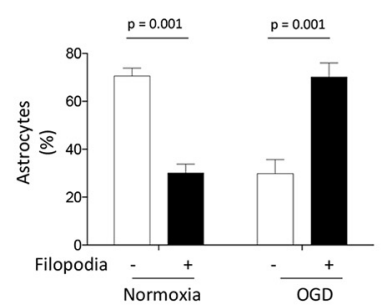

E

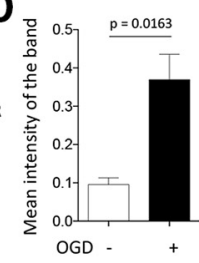

I

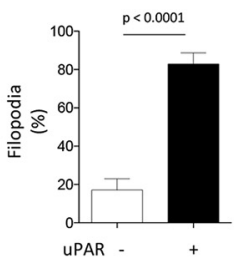

Figure 1. Astrocytic expression of uPAR. $\boldsymbol{A}$, Representative micrographs of an unstimulated WT astrocyte immunostained with antibodies against GFAP (red, $\boldsymbol{a}$ ) and uPAR (green, $\boldsymbol{b}$ ). Blue is the nuclear marker Hoechst 33342. c, Merged images. Magnification: $60 \times$. Thin and thick arrows in $\boldsymbol{b}$ denote perinuclear and cortical expression of uPAR, respectively. $\boldsymbol{B}$, Percentage of uPAR-positive and UPAR-negative astrocytes among 155 unstimulated cells examined from four different cultures. Error bars indicate SEM. Statistical analysis was performed with two-tailed $t$ test. $\boldsymbol{C}, \boldsymbol{D}$, Representative Western blot analysis $(\boldsymbol{C})$ and mean intensity of the band $(\boldsymbol{D})$ of uPAR expression in WT astrocytes either kept under normoxic conditions or after $1 \mathrm{~h}$ of exposure to $0 \mathrm{GD}$. $n=4$. Statistical analysis performed with two-tailed $t$ test. $\boldsymbol{E}, \boldsymbol{F}$, Representative Western blot analysis $(\boldsymbol{E})$ and quantification of the mean intensity of the band $(\boldsymbol{F})$ of uPAR expression in the plasma membrane of WT astrocytes. Biotin labeling was used to assess uPAR expression under normoxia or after $1 \mathrm{~h}$ of exposure to OGD. Lines indicate SEM. $n=4$. Statistical analysis was performed with two-tailed $t$ test. $\mathbf{G}$, Representative micrographs of WT astrocytes immunostained with phalloidin (red in $\boldsymbol{a}$ and $\boldsymbol{d}$ ) and anti-uPAR antibodies (green in $\boldsymbol{b}$ and $\boldsymbol{e}$ ) under normoxia (control, C) or after $1 \mathrm{~h}$ of exposure to $0 \mathrm{GD}$ conditions. $\boldsymbol{c}$ and $\boldsymbol{f}$ correspond to merged images. Blue is the nuclear marker Hoechst 33342. Arrows in $\boldsymbol{e}$ depict uPAR-positive filopodia. Magnification: $60 \times$. $\boldsymbol{H}$, Mean percentage of astrocytes exhibiting filopodial extensions after incubation under normoxic conditions, or after $1 \mathrm{~h}$ of exposure to $0 \mathrm{GD} . n=150$ astrocytes examined from five different cultures. Error bars indicate SEM. Statistical analysis was performed with two-way ANOVA with Holm-Sidak correction. I, Percentage of uPAR-positive and uPAR-negative filopodia in astrocytes exposed to $1 \mathrm{~h}$ of $O G D$ conditions. $n=150$ astrocytes examined from five different cultures. Error bars indicate SEM. Statistical analysis was performed with two-tailed $t$ test.

laser-scanning microscope (Olympus) with the pinhole configured at $1 \times$ from an area located within $1 \mathrm{~mm}$ around the ischemic core. Synapses, identified by their immunoreactivity to PSD-95 and bassoon, were quantified with the plugin "puncta analyzer" in ImageJ and images were taken at $60 \times$ magnification and electronically enhanced 252 times Values are expressed as the number of synapses per $2500 \mu \mathrm{m}^{2}$.

ELISA. The culture medium from WT astrocytes and neurons was collected $0,1,3$, and $24 \mathrm{~h}$ after $3 \mathrm{~h}$ (in astrocytes) and $5 \mathrm{~min}$ (in neurons) of OGD and the concentration of UPA was determined with an ELISA kit following the manufacturer's instructions. Briefly, $100 \mu \mathrm{l}$ of supernatant was added to antibody-coated wells for $30 \mathrm{~min}$, washed, incubated with $100 \mu \mathrm{l}$ of anti-uPA antibodies for $30 \mathrm{~min}$, washed 3 times, incubated with $100 \mu \mathrm{l}$ of secondary antibody, washed again, and incubated with $100 \mu \mathrm{l}$ of tetramethylbenzidine substrate for $5 \mathrm{~min}$. The reaction was stopped using $50 \mu \mathrm{l}$ of $1 \mathrm{~N} \mathrm{HCl}$, and the absorbance of each well was measured at $450 \mathrm{~nm}$. The concentration of uPA in each sample was determined using a standard curve.

Statistical analysis. Statistical analysis was performed with two-tailed $t$ test and one- or two-way ANOVA, with Tukey's, Holm-Sidak, or Dunnett's corrections, as appropriate, and described in each figure legend. $p$-values of $<0.05$ were considered significant.

\section{Results \\ uPAR expression in astrocytes}

First, we performed an immunocytochemical analysis to study the expression of uPAR in unstimulated WT astrocytes. We found that most of these cells have a polygonal shape and that $82.13 \pm 3 \%$ of them exhibit uPAR immunoreactivity, mostly in their perinuclear area and in limited zones of the cell membrane (Fig. $1 A, B ; n=155 ; p<0.001$, two-tailed $t$ test). It is known that hypoxia induces the expression of uPAR in different cell types (Yoon et al., 2006; Wu et al., 2014; Merino et al., 2017). Consistent with these observations, our Western blot analyses showed an increase in the expression of astrocytic uPAR after $60 \mathrm{~min}$ of exposure to OGD conditions (Fig. 1C,D) and our biotin-labeling studies indicated that hypoxia not only induces the expression of uPAR, but also its recruitment to the astrocytic plasma membrane (Fig. 1E,F). To further characterize these results, we performed an immunocytochemical analysis with phalloidin and anti-uPAR antibodies in nonpermeabilized astrocytes either kept under normoxic conditions or afater $60 \mathrm{~min}$ of OGD. We not only confirmed that hypoxia causes a sharp increase in the expression of uPAR on the astrocytic membrane, but also that it induces the formation of filopodia (Fig. $1 \mathrm{Ge}, \mathrm{H}$ ), $82.88 \pm 5.8 \%$ of which exhibit uPAR immunoreactivity (Fig. $1 I ; n=150 ; p<$ 0.0001 , two-tailed $t$ test).

\section{Effect of uPA- uPAR binding on astrocytic activation}

Our data show that OGD induces membrane recruitment of UPAR and morphological changes indicative of astrocytic activation. To determine whether both findings are linked, we studied the expression of GFAP, a marker of astrocytic activation (Yang and Wang, 2015), in WT and $\mathrm{uPAR}^{-1-}$ astrocytes either kept under normoxic conditions or after $60 \mathrm{~min}$ of exposure to OGD conditions. Our finding that OGD increases the expression of GFAP in WT but not $\mathrm{uPAR}^{-1-}$ astrocytes (Fig. $2 A, B$ ) indicates that $\mathrm{uPAR}$ mediates hypoxia-induced astrocytic activation. Because cerebral ischemia is an effective inductor of astrocytic activation (Li et al., 2008), we then used an in vivo model of ischemic stroke to study the expression of GFAP in ischemic tissue and in a comparable area from the contralateral nonischemic hemisphere of $\mathrm{WT}, \mathrm{uPA}^{-1-}$, and $\mathrm{uPAR}^{-1-}$ mice $4 \mathrm{~d}$ after tMCAO, followed by intravenous treatment with either saline solution or ruPA ( $n=5$ animals per experimental group). Our results show that GFAP expression increases in the ischemic tissue of WT mice, but not $\mathrm{uPA}^{-1-}$ or $\mathrm{uPAR}^{-1-}$ mice. Furthermore, we found that treatment with ruPA increases GFAP expression in $\mathrm{uPA}^{-1-}$ but not $\mathrm{uPAR}^{-/-}$mice (Fig. $2 C, D$ ). To further confirm that the 
A

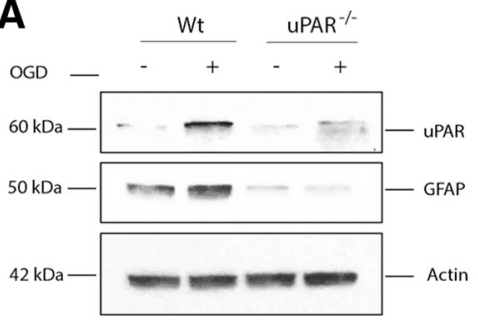

B

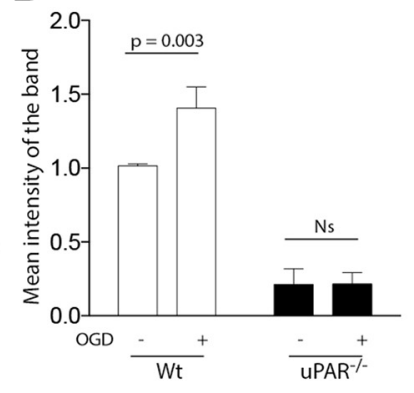

E

GFAP

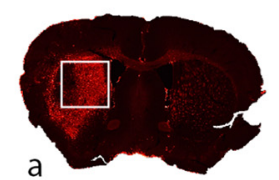

UPAR $^{-/-}$
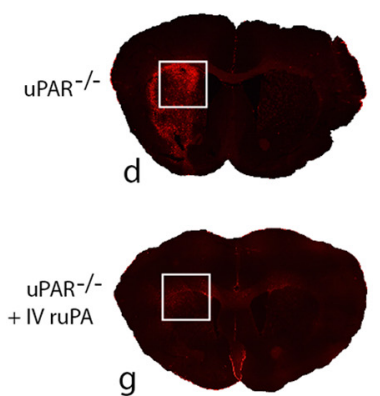

g
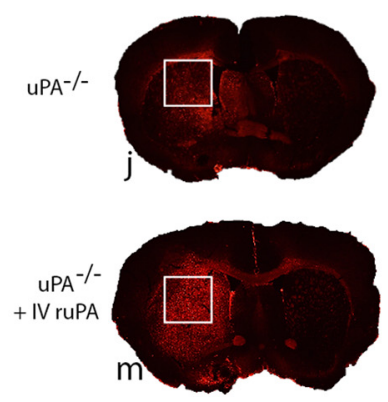

Hoechst
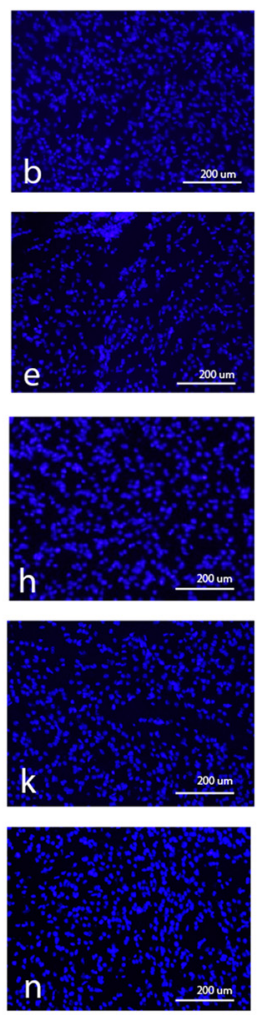

GFAP
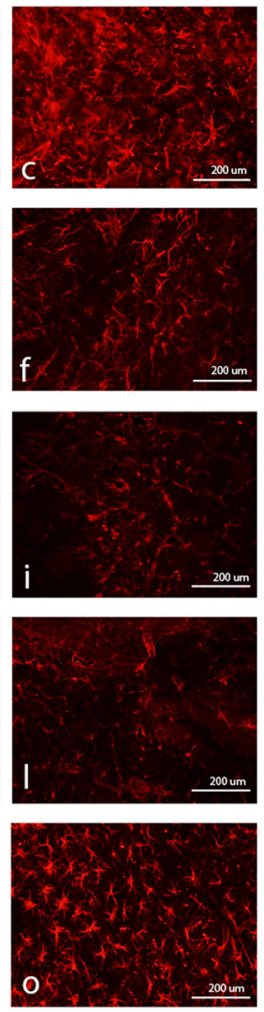

C

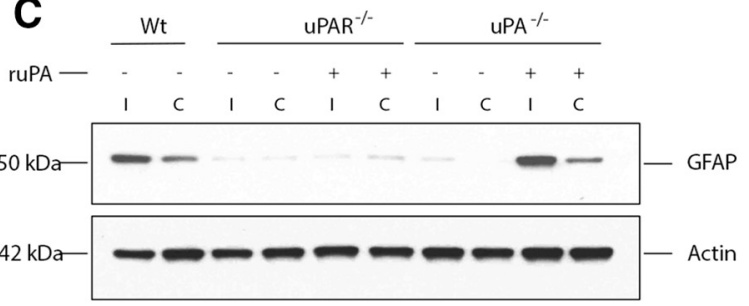

D $\underline{\mathrm{p}=0.0086} \quad \underline{\mathrm{p}=0.04}$

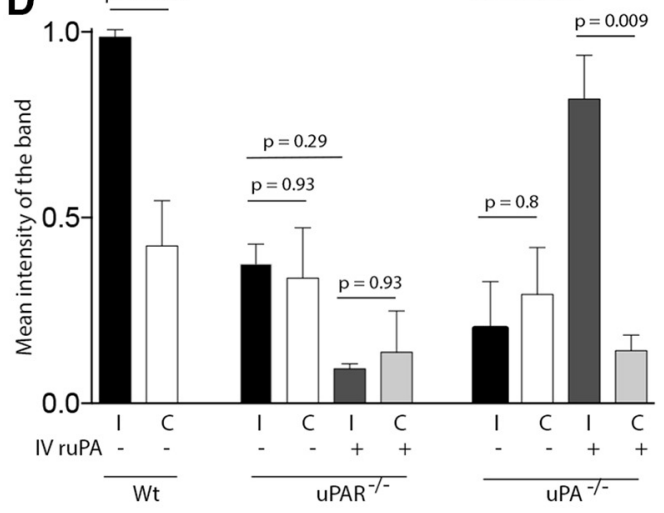

F

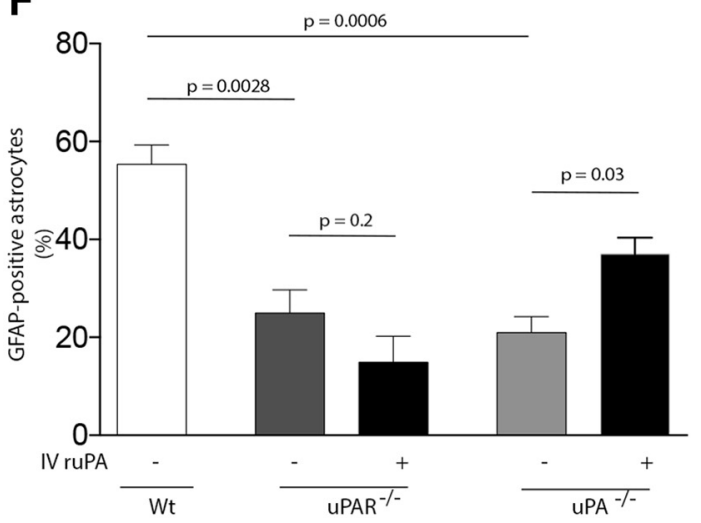

Figure 2. uPA binding to uPAR mediates cerebral ischemia-induced astrocytic activation. $\boldsymbol{A}, \boldsymbol{B}$, Representative Western blotting for uPAR and GFAP expression ( $\boldsymbol{A}$ ) and quantification of the mean intensity of the band $(\boldsymbol{B})$ in WT and uPAR ${ }^{-1-}$ astrocytes kept under normoxic conditions or exposed to $1 \mathrm{~h}$ of $0 \mathrm{GD}$ conditions. $n=4$ observations per experimental condition. Lines indicate SEM. Statistical analysis was performed with two-way ANOVA with Holm-Sidak correction. $\boldsymbol{C}, \boldsymbol{D}$, Representative Western blot analysis $(\boldsymbol{C})$ and quantification of the mean intensity of the band $(\boldsymbol{D})$ of GFAP expression in the ischemic (i) tissue and a comparable area in the contralateral (c) nonischemic hemisphere of WT, uPAR ${ }^{-1-}$ and uPA ${ }^{-1-}$ mice $96 \mathrm{~h}^{-1}$ fter tMCA0 and intravenous treatment with either saline solution or ruPA. $n=4$ animals per experimental group. Lines indicate SEM. Statistical analysis was performed with two-way ANOVA with Holm-Sidak correction. $\boldsymbol{E}$, Representative micrographs of GFAP immunostaining in the ischemic area of WT, uPAR ${ }^{-1-}$ and $\mathrm{UPA}^{-1-}$ mice $96 \mathrm{~h}$ after $\mathrm{MCA} 0$ and intravenous treatment with either saline solution or ruPA. Blue is the nuclear marker Hoechst 33342. $n=5$ animals per experimental condition. Magnification is $4 \times$ in $\boldsymbol{a}, \boldsymbol{d}, \boldsymbol{g}, \boldsymbol{j}$, and $\boldsymbol{m} . \boldsymbol{b}, \boldsymbol{c}, \boldsymbol{e}, \boldsymbol{f}, \boldsymbol{h}, \boldsymbol{i}, \boldsymbol{k}, \boldsymbol{I}, \boldsymbol{n}$ and $\boldsymbol{o}$ correspond to a $20 \times$ magnification of the area denoted by the corresponding white squares in $\boldsymbol{a}, \boldsymbol{d}, \boldsymbol{g}, \boldsymbol{j}$, and $\boldsymbol{m}$. $\boldsymbol{F}$, Mean percentage of GFAP-positive astrocytes in relation to the total number of Hoechst-positive cells examined (denoted in parenthesis for each experimental group) in the ischemic tissue of WT ( $n=6667$ cells), uPAR ${ }^{-1-}\left(n=5456\right.$ cells), and uPA ${ }^{-1-}$ mice $(n=5234$ cells $) 96 \mathrm{~h}^{-}$after tMCA0. A subgroup of uPAR ${ }^{-1-}$ and uPA ${ }^{-1-}$ mice ( $n=5$ per strain) were treated intravenously with ruPA ( $n=5748$ and $n=6452$ cells examined, respectively). Lines indicate SEM. Statistical analysis was performed with one-way ANOVA with Holm-Sidak correction.

observed increase in GFAP expression is due to astrocytic activation, we performed an immunohistochemical analysis with antiGFAP antibodies in sections from the ischemic tissue of WT, $\mathrm{uPA}^{-1-}$, and $\mathrm{uPAR}^{-1-}$ mice $(n=5$ animals per experimental group) exposed to the experimental conditions described above. Our results corroborated our initial observations that uPA binding to UPAR mediates cerebral ischemia-induced astrocytic activation (Fig. 2E,F).

To determine whether uPA is sufficient to induce astrocytic activation and whether this effect requires the conversion of plasminogen into plasmin, we quantified the number of GFAPpositive astrocytes $48 \mathrm{~h}$ after the injection of a $5 \mathrm{~nm}$ concentration of either uPA or its ATF (devoid of proteolytic activity) or a comparable volume of PBS into the striatum of WT, $\mathrm{uPA}^{-1-}$, and $\mathrm{uPAR}^{-1-}$ mice ( $n=3$ animals per experimental group). Our data indicate that uPA induces astrocytic activation in WT but not $\mathrm{uPAR}^{-1-}$ mice by a mechanism that does not require plasmin generation (Fig. $3 A, B$ ). To ensure that the effect of uPA is mediated by its binding to astrocytic uPAR, we studied the expression of GFAP in WT and $\mathrm{UPAR}^{-/-}$astrocytes incubated for 
A
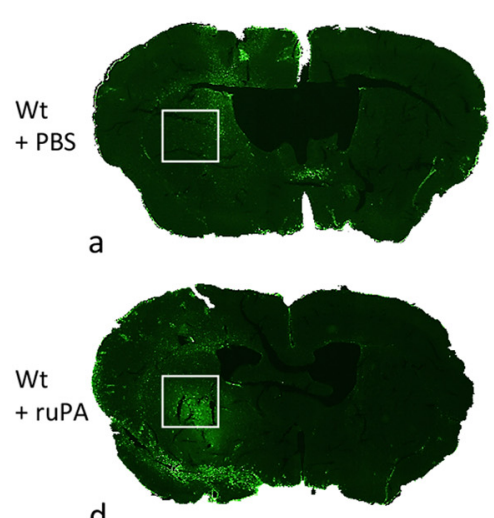

d

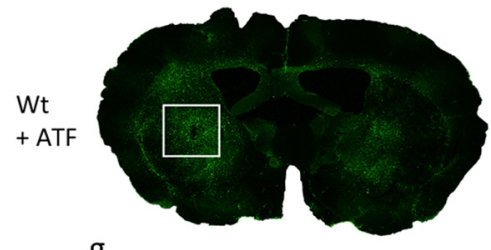

g
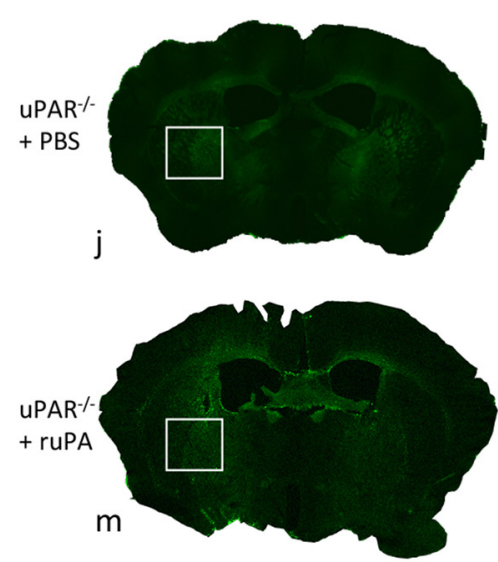

GFAP
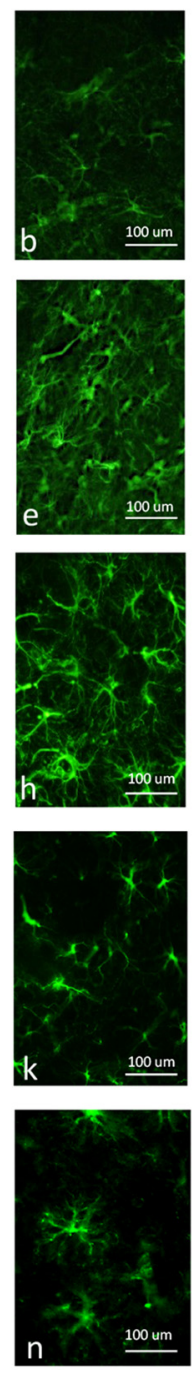

Hoechst
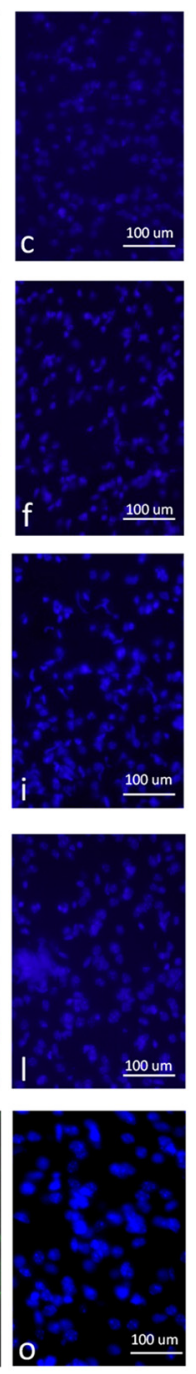

B

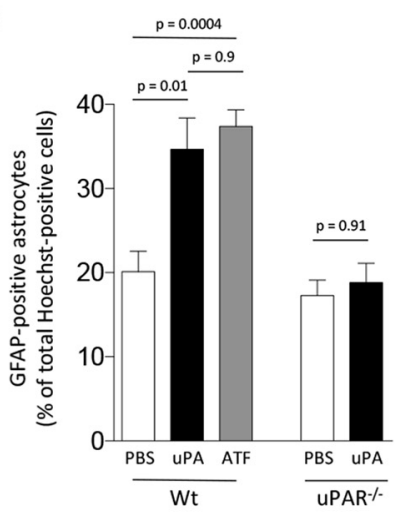

C

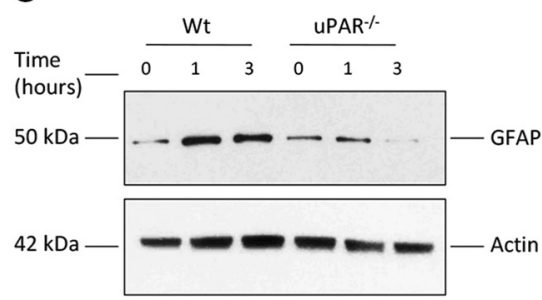

D

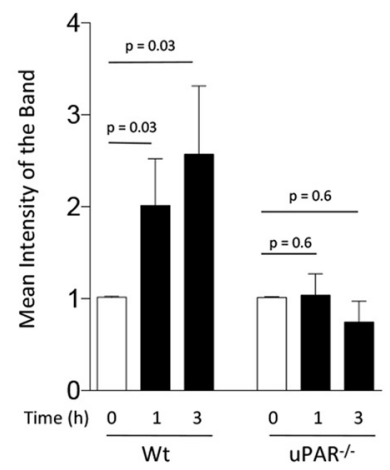

Figure 3. UPA- UPAR binding is sufficient to induce plasmin-independent astrocytic activation in vivo. $\boldsymbol{A}, \boldsymbol{a}, \boldsymbol{d}, \boldsymbol{g}, \boldsymbol{j}$, and $\boldsymbol{m}$ correspond to representative brain sections from WT and uPAR ${ }^{-1-}$ mice immunostained with antibodies against GFAP (green) and the nuclear marker Hoechst 33342 (blue) $48 \mathrm{~h}$ after the intrastriatal injection of $5 \mathrm{~nm}$ uPA, its ATF (devoid of proteolytic activity), or a comparable volume of PBS. $\boldsymbol{b}, \boldsymbol{c}, \boldsymbol{e}, \boldsymbol{f}, \boldsymbol{h}, \boldsymbol{i}, \boldsymbol{k}, \boldsymbol{l}, \boldsymbol{n}$ and $\boldsymbol{o}$ correspond to a $20 \times$ magnification of the area denoted by the white square in each experimental group. $\boldsymbol{B}$, Mean percentage of GFAP-positive astrocytes in relation to the total number of Hoechst-positive cells examined (denoted in parenthesis for each experimental group) $48 \mathrm{~h}$ after the intrastriatal injection of PBS ( $n=2020$ cells examined), UPA (2988 cells examined), or ATF (1597 cells examined) in WT mice or PBS (1916 cells examined) or uPA (2241 cells examined) in uPAR ${ }^{-1-}$ mice. Lines indicate SEM. $n=3$ animals per experimental condition. Statistical analysis was performed with one-way ANOVA with Holm-Sidak correction. $\boldsymbol{C}, \boldsymbol{D}$, Representative Western blot analysis $(\boldsymbol{C})$ and quantification of the mean intensity of the band (D) of GFAP expression in WT and uPAR ${ }^{-1-}$ astrocytes after $0-3 \mathrm{~h}$ of incubation with $5 \mathrm{~nm} \mathrm{uPA}$. Lines indicate SEM. $n=4$ per experimental condition. Statistical analysis was performed with two-tailed $t$ test.

$0-3 \mathrm{~h}$ with $5 \mathrm{~nm} \mathrm{uPA}$. We found that uPA induces the expression of GFAP in WT but not $\mathrm{uPAR}^{-1-}$ astrocytes (Fig. 3C,D). Together with our in vivo observations, these data indicate that binding of uPA to astrocytic uPAR is necessary and sufficient to induce astrocytic activation.

\section{ERK1/2-regulated STAT3 phosphorylation mediates} uPA-induced astrocytic activation

Because activated astrocytes exhibit strong ERK1/2 phosphorylation (Jiang et al., 2002), we then investigated the expression of ERK1/2 phosphorylated at Thr202 and Tyr204 in WT astrocytes incubated for $0-30 \mathrm{~min}$ with $5 \mathrm{nM} \mathrm{uPA}$. Our data indicate that uPA induces astrocytic ERK1/2 phosphorylation (Fig. $4 A, B$ ). To determine whether uPAR mediates ERK1/2 activation and to test the in vivo significance of our findings, we performed similar observations with brain extracts from WT and $\mathrm{uPAR}^{-1-}$ mice harvested after $30 \mathrm{~min}$ of tMCAO or sham operation $(n=4$ animals per experimental group). We found that UPAR mediates cerebral ischemia-induced ERK1/2 activation (Fig. 4C,D). Then, to investigate whether ERK1/2 mediates the effect of uPA on astrocytic activation, we studied the expression of GFAP in WT astrocytes incubated with $5 \mathrm{nM}$ uPA alone or in the presence of $10 \mu \mathrm{M}$ the ERK1/2 inhibitor SL327. In addition, we quantified the area immunoreactive to GFAP and the number of GFAP-positive astrocytes in brain sections of WT mice $48 \mathrm{~h}$ after the intraventricular administration of $2 \mu \mathrm{l}$ of either a $2.2 \mathrm{~mm}$ solution of SL327 or PBS, followed by the intrastriatal injection of $5 \mathrm{nM} \mathrm{uPA}$. We found that ERK1/2 mediates the effect of uPA on astrocytic activation in vitro (Fig. $4 E, F$ ) and in vivo (Fig. $4 G-J ; n=4$ animals per experimental condition; $p<0.0001$; two-tailed $t$ test).

Because phosphorylation and nuclear translocation of STAT3 is required for astrocytic activation (Herrmann et al., 2008), we 
A

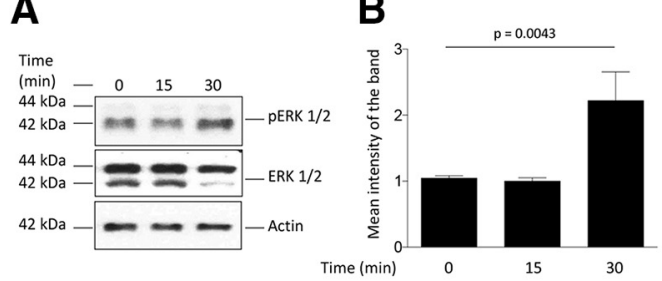

F

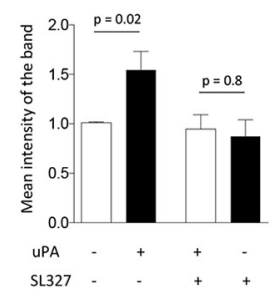

G

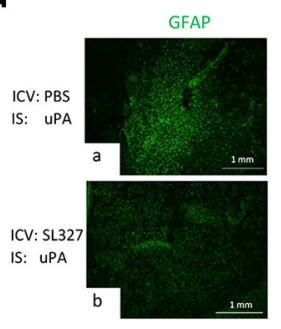

C

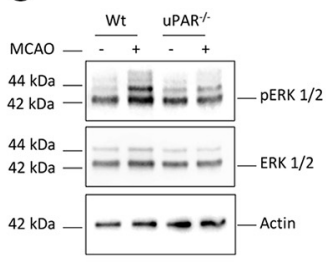

H

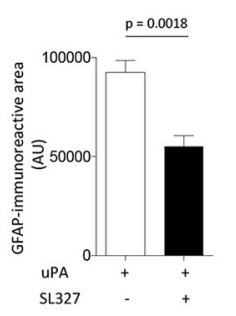

D

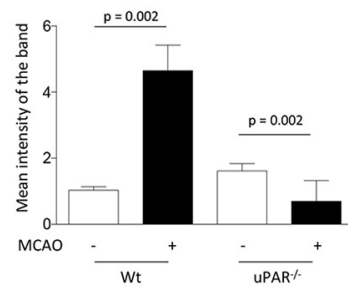

I
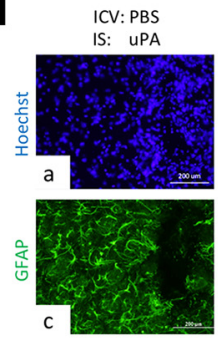

E

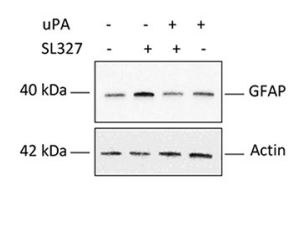

J

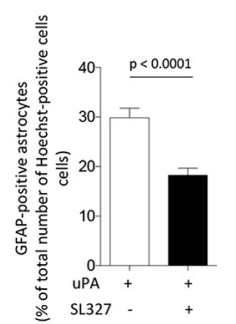

Figure 4. ERK1/2-regulated STAT3 phosphorylation mediates uPA-induced astrocytic activation. $A, B$, Representative Western blot analysis $(A)$ and quantification of the mean intensity of the band $(\boldsymbol{B})$ of pERK1/2 and total ERK1/2 expression in WT astrocytes incubated $0-30$ min with $5 \mathrm{~nm} \mathrm{uPA.} n=3$ observations per experimental condition. Lines indicate SEM. Statistical analysis was performed with one-way ANOVA with Holm-Sidak correction. $\boldsymbol{C}, \boldsymbol{D}$, Representative Western blot analysis $(\boldsymbol{C})$ and quantification of the mean intensity of the band (D) of pERK1/2 and total ERK1/2 expression in the ischemic tissue of WT and uPAR ${ }^{-1-}$ mice subjected to 30 min of tMCAO. Controls correspond to sham-operated WT and uPAR ${ }^{-1-}$ animals. Statistical analysis was performed with one-way ANOVA with Tukey's correction. $n=4$ animals per experimental group. $\boldsymbol{E}$, $\boldsymbol{F}$, Representative Western blot analysis $(\boldsymbol{E})$ and quantification of the mean intensity of the band $(\boldsymbol{F})$ of GFAP expression in WT astrocytes incubated $3 \mathrm{~h}$ with $5 \mathrm{~nm} \mathrm{uPA}$ alone or in the presence of the ERK1/2 inhibitor SL327. $n=3$ observations per experimental group. Statistical analysis was performed with two-tailed $t$ test. G, Representative micrograph of the striatum of WT mice stained with anti-GFAP antibodies $48 \mathrm{~h}$ after the intracerebroventricular (ICV) administration of either PBS (a), or SL327 (b) followed by the intrastriatal (IS) injection of $5 \mathrm{~nm}$ UPA. Magnification, $4 \times$. $\boldsymbol{H}$, Mean area immunoreactive to anti-GFAP antibodies in the striatum of WT mice subjected to the experimental conditions described in $\boldsymbol{E}$. Lines indicate SEM. $n=4$ animals per experimental condition. Statistical analysis was performed with two-tailed $t$ test. $I, J$, Representative micrographs at $20 \times$ magnification $(I)$ and mean percentage of GFAP-positive astrocytes in relation to the total number of Hoechst-positive cells examined (J; shown in parentheses for each experimental group) $48 \mathrm{~h}$ after the intrastriatal injection of uPA preceded by the intracerebroventricular injection of either PBS (7439 cells examined) or SL327 (7798 cells examined). Lines indicate SEM. $n=4$ animals per experimental condition. Statistical analysis was performed with two-tailed $t$ test.

investigated the expression of STAT3 phosphorylated at Tyr705 (pSTAT3) in WT astrocytes treated with $5 \mathrm{~nm}$ uPA alone or in the presence of SL327. Our data indicate that uPA induces STAT3 activation in astrocytes and that this effect is abrogated by ERK1/2 inhibition (Fig. $5 A, B ; n=90-128$ cells; $p<0.0001$, one-way ANOVA). Then, to study the effect of uPA on STAT3 phosphorylation in vivo, we costained with anti-GFAP and antipSTAT3 antibodies brain slices of WT mice obtained $48 \mathrm{~h}$ after the intraventricular administration of either SL327 or PBS, followed by the intrastriatal injection of $5 \mathrm{nM} \mathrm{uPA}$ or a comparable volume of PBS. We found that uPA induces astrocytic STAT3 activation in vivo and that this effect is abrogated by ERK1/2 inhibition (Fig. $5 C, D ; n=4$ animals per experimental group; $p<$ 0.0001 , one-way ANOVA). To determine whether uPAR mediates STAT3 activation and to test the in vivo significance of our findings, we performed similar observations in the ischemic brain of WT and $\mathrm{uPAR}^{-1-}$ mice subjected to $30 \mathrm{~min}$ of tMCAO. Our data indicate that uPAR mediates cerebral ischemia-induced STAT3 activation (Fig. $5 E, F ; n=4$ animals per experimental group; $p<0.0001$, two-way ANOVA).

\section{Synaptic effect of uPA-induced astrocytic activation}

To determine the source of uPA that upon interaction with uPAR on the astrocytic membrane leads to astrocytic activation, we used an ELISA to measure the release of UPA in the culture medium of WT astrocytes $0-24 \mathrm{~h}$ after exposure to $3 \mathrm{~h}$ of OGD. Surprisingly, we found that OGD does not induce the release of astrocytic uPA (data not shown). In contrast, our earlier work indicates that neurons release uPA during the recovery phase from an acute hypoxic injury and that uPA binding to uPAR promotes functional recovery after an acute ischemic injury
(Wu et al., 2014). It is known that synaptic repair underlies the recovery of neurological function after an ischemic stroke (Hofmeijer and van Putten, 2012). Therefore, based on these observations and on the cross talk between neurons and astrocytes in the synapse (Perea et al., 2009), we postulated that binding of uPA released from neurons to uPAR recruited to the astrocytic plasma membrane during the recovery phase from a hypoxic injury contributes to repair the synapse that has suffered a hypoxic insult.

To test this hypothesis, we first quantified the number of synapses, denoted by their immunoreactivity to PSD-95 (which delineates the postsynaptic density), and bassoon (which identifies the presynaptic compartment), in WT neurons $24 \mathrm{~h}$ after $0-30$ min of exposure to OGD. We found that $5 \mathrm{~min}$ was the shortest OGD time that caused a significant decrease in the number of synapses (Fig. $6 A ; n=30 ; p<0.0001$, one-way ANOVA). Furthermore, our propidium iodide uptake experiments showed that $5 \mathrm{~min}$ of OGD did not induce cell death (Fig. $6 B ; n=28 ; p=$ 0.89 , one-way ANOVA). Then, we measured the concentration of UPA in the culture medium of WT neurons $0-24 \mathrm{~h}$ after exposure to $5 \mathrm{~min}$ of OGD. Our data indicate that neurons release uPA during the recovery phase from 5 min of OGD (Fig. $6 C ; n=5$ observations per time point; $p=0.007$, one-way ANOVA). In summary, these data show that $5 \mathrm{~min}$ of OGD induce both a significant decrease in the number of synapses and the release of uPA without causing cell death. Finally, to investigate whether astrocytes enter in contact with the synapse when placed in the presence of neurons, extracts from synaptoneurosomes prepared from WT neurons maintained either alone or in the presence of astrocytes were immunoblotted with antibodies against synaptophysin (detects the axonal bouton), PSD-95, and GFAP. Our data 
A

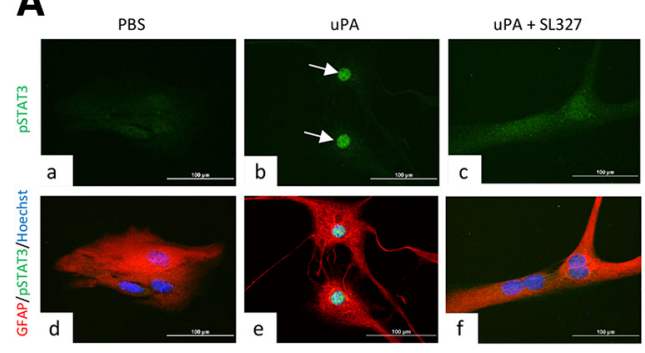

B

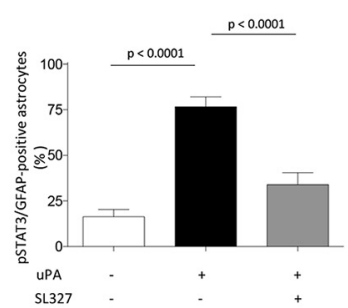

C

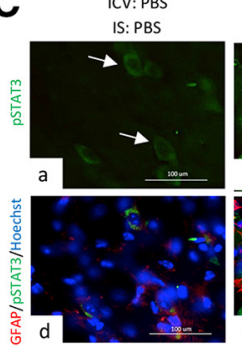

UPAR - -

E

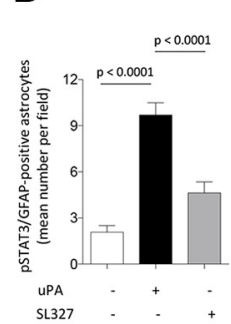

Wt

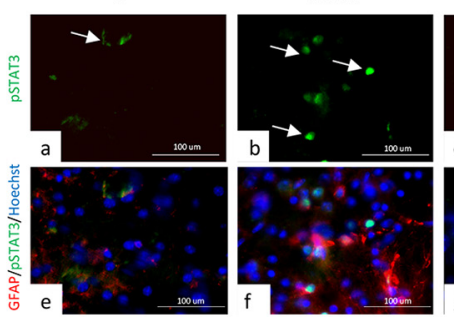

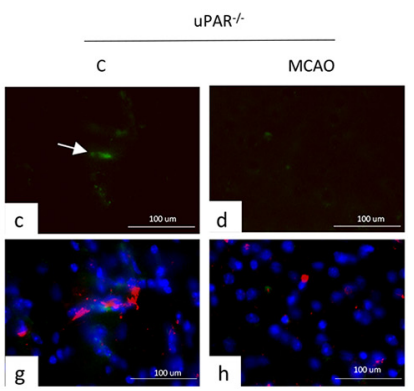

ICV: SL327 IS: UPA

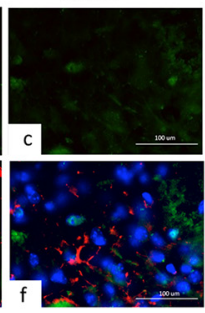

F

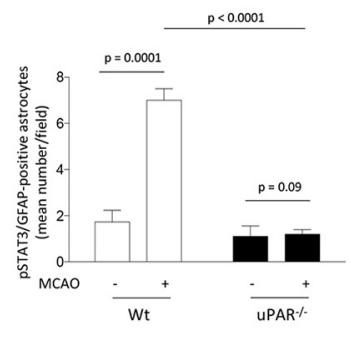

Figure 5. UPA induces ERK1/2-mediated astrocytic STAT3 phosphorylation. $\boldsymbol{A}$, Representative micrograph of WT astrocytes treated during $1 \mathrm{~h}$ with PBS $(\boldsymbol{a}, \boldsymbol{d}), 5 \mathrm{~nm}$ uPA alone $(\boldsymbol{b}, \boldsymbol{e})$, or in the presence of $10 \mu \mathrm{mSL} 327(\boldsymbol{c}, \boldsymbol{f})$. Red is GFAP, green is pSTAT3, and blue is the nuclear marker Hoechst 33342. Arrows in $\boldsymbol{b}$ denote examples of pSTAT3-positive nuclei. $\boldsymbol{B}$, Mean percentage of astrocytes with pSAT3-positive nuclei after $1 \mathrm{~h}$ of treatment with PBS ( $n=90$ cells examined), $5 \mathrm{~nm} \mathrm{uPA} \mathrm{(} n=107$ cells examined), or a combination of uPA and SL327 ( $n=128$ cells examined). $0 \mathrm{bservations}$ were repeated in three different neuronal cultures. Lines indicate SEM. Statistical analysis was performed with one-way ANOVA with Tukey's correction. C, Representative micrographs of brain sections cut through the striatum of WT mice ( $n=4$ per condition) and costained with anti-GFAP (red) and pSTAT3 (green) antibodies $48 \mathrm{~h}$ after the intracerebroventricular (ICV) administration of either PBS $(\boldsymbol{a}, \boldsymbol{b}, \boldsymbol{d}$, and $\boldsymbol{e}$ ) or SL327 ( $\boldsymbol{c}$ and $\boldsymbol{f})$, followed by the intrastriatal injection of either of either $5 \mathrm{nM}$ of uPA ( $\boldsymbol{b}$ and $\boldsymbol{e}$ ) or a comparable volume of PBS ( $\boldsymbol{a}$ and $\boldsymbol{d}) . n=4$ animals per experimental condition. Magnification, $20 \times . D$, Mean number of pSTAT3-immunoreactive astrocytes per field at $40 \times$ magnification in the striatum of WT mice exposed to the experimental conditions described in C. Lines depict SEM. $n=4$ animals per experimental condition. Statistical analysis was performed with one-way ANOVA with Tukey's correction. E, Representative micrographs of pSTAT 3 (green), GFAP (red), and Hoechst (blue) staining in the area surrounding the necrotic core of WT $(\boldsymbol{a}, \boldsymbol{b}, \boldsymbol{e}, \boldsymbol{f})$ and uPAR ${ }^{-/-}(\boldsymbol{c}, \boldsymbol{d}, \boldsymbol{g}, \boldsymbol{h})$ mice $48 \mathrm{~h}$ after 30 min of tMCA0. Controls (C) correspond to a comparable area in sham-operated animals. $n=4$ animals per experimental group. Magnification, $20 \times$. Arrows in $\boldsymbol{a}, \boldsymbol{b}$, and $\boldsymbol{c}$ denote examples of pSTAT3-positive astrocytes. $\boldsymbol{F}$, Mean number of Hoechstpositive cells immunoreactive to GFAP and pSTAT3 antibodies per field at $40 \times$ magnification in WT and UPAR ${ }^{-1-}$ mice subjected to the experimental conditions described in $E$. $n=4$ animals per experimental group. Statistical analysis was performed with two-way ANOVA with Tukey's correction.

indicate that, in this coculture system, astrocytes enter in direct contact with the synapse (Fig. 6D).

Based on these results, we first counted the number of synapses, as described in the Materials and Methods, in WT neurons maintained under normoxic conditions alone or in the presence of WT or uPAR ${ }^{-1-}$ astrocytes. We found no difference in the number of synapses between the three experimental groups (Fig. $6 E, G ; n=50 ; p>0.9$, one-way ANOVA). To perform similar observations under hypoxic conditions, in a second group of experiments, we exposed WT cerebral cortical neurons to $5 \mathrm{~min}$ of OGD (to induce a drop in the number of synapses without causing cell death). Then, cells were either kept alone or transferred to wells containing WT or uPAR ${ }^{-1-}$ astrocytes maintained under normoxic conditions or previously activated by exposure to $3 \mathrm{~h}$ of OGD. Twenty-four hours later, neurons were fixed and the number of synapses quantified. We found that, compared with neurons maintained under normoxic conditions, $5 \mathrm{~min}$ of OGD induced a $74.46 \pm 2.59 \%$ decrease in the number of synapses $(n=50 ; p<0.0001$, one-way ANOVA). Significantly, when neurons were transferred after 5 min of OGD to wells containing WT astrocytes maintained under normoxic conditions, there was an attenuation in the percentage of synaptic loss $(67.76 \pm 3.47 \%)$ that yet did not reach statistical significance when compared with neurons kept alone $(n=50 ; p=0.9$; oneway ANOVA. Fig. $6 F a, F b, G)$. In contrast, we observed a significant attenuation in synaptic loss when neurons were transferred after 5 min of OGD to wells containing WT astrocytes previously exposed to OGD conditions $(41.16 \pm 3.47 \% ; n=50 ; p=$ $<0.0001$ compared with synaptic loss in neurons kept alone or transferred to wells containing astrocytes maintained under normoxic conditions, one-way ANOVA; Fig. $6 F c, G$ ). More significantly, we failed to detect synaptic recovery when neurons were transferred to plates containing $\mathrm{uPAR}^{-1-}$ astrocytes previously exposed to OGD conditions $(n=50 ; p=0.8$ when compared with neurons either kept alone or transferred to plates containing WT astrocytes maintained under normoxic conditions; one-way ANOVA).

To determine whether binding of uPA released from neurons to astrocytic uPAR mediates the observed effect on synaptic recovery, we performed similar observations in $\mathrm{uPA}^{-1-}$ neurons recovered during $24 \mathrm{~h}$ from $5 \mathrm{~min}$ of OGD in the presence of WT astrocytes previously exposed to OGD conditions. Our data show that, in contrast to WT neurons recovered in the presence of WT astrocytes previously activated by OGD, exposure of $\mathrm{uPA}^{-1-}$ neurons to wells containing OGD-activated WT astrocytes not only failed to induce synaptic recovery, but instead caused a small but significant decrease in the number of synaptic contacts (Fig. $6 H, I ; n=35 ; p=0.0004$, one-way ANOVA). Together, these results indicate that binding of neuronal uPA to astrocytic uPAR promotes synaptic recovery after a hypoxic injury.

To determine the in vivo significance of these observations, we quantified the number of synapses either within $1 \mathrm{~mm}$ of the border of the ischemic core or in a comparable area of the nonischemic brain in WT and Plau GFDhu/GFDhu mice in which a fouramino acid substitution into the growth factor domain of uPA prevents its binding to uPAR (Connolly et al., 2010) immediately after $30 \mathrm{~min}$ of tMCAO (acute ischemia), $4 \mathrm{~d}$ after $30 \mathrm{~min}$ of tMCAO (recovery period, enough for uPA-uPAR binding to in- 

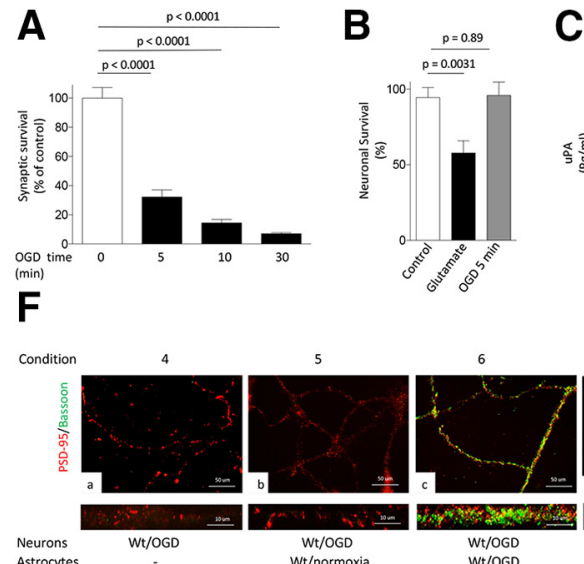

C

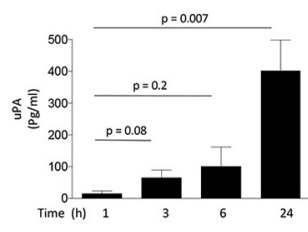

G
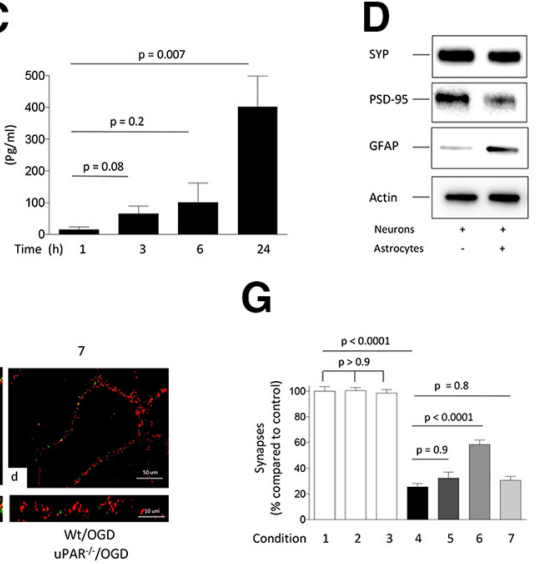

E
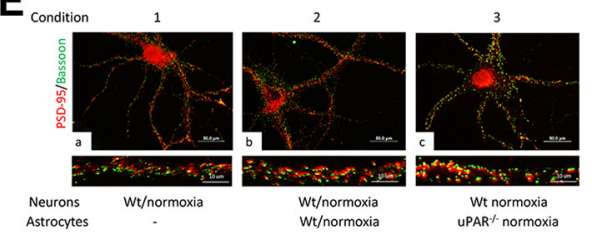

H
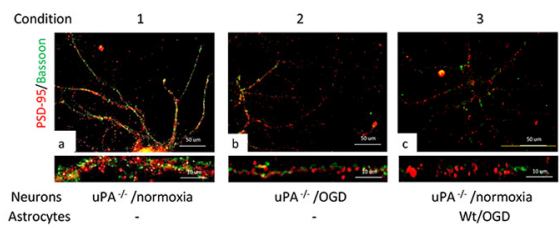
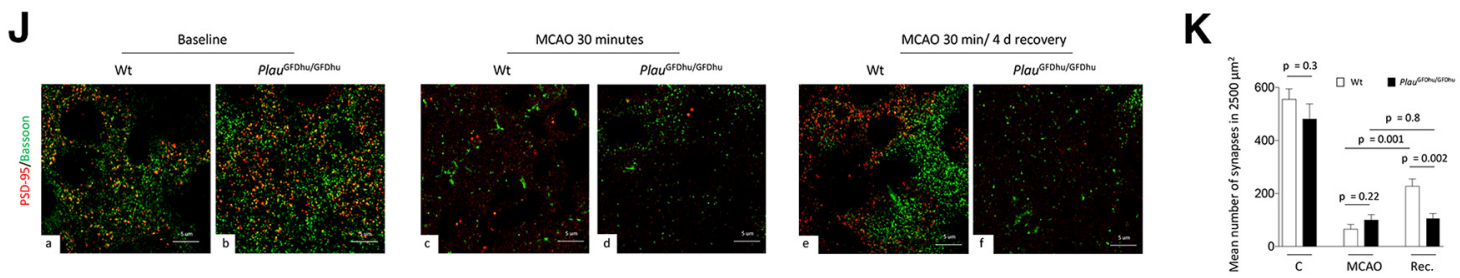

Figure 6. Effect of UPA- UPAR binding on synaptic recovery. $A$, Mean percentage of synaptic contacts immunoreactive to both PSD-95 and bassoon in cultures of WT cerebral cortical neurons kept under normoxia or exposed to $0-30$ min of $0 G D$ conditions. $n=30$ neurons examined per experimental condition in cells from three different cultures. Lines indicate SEM. Statistical analysis was performed with one-way ANOVA with Holm-Sidak correction. $\boldsymbol{B}$, Mean percentage of alive neurons either under physiological conditions (white bar; $n=33$ cells examined) or exposed for 5 min to either $50 \mu \mathrm{m}$ glutamate (black bar; $n=30$ cells examined) or OGD (gray bar; $n=28$ cells examined). Each observation was repeated in three different neuronal cultures. Lines indicate SEM. Statistical analysis was performed with one-way ANOVA with Holm-Sidak correction. C, Mean concentration of uPA in the culture medium of WT cerebral cortical neurons $1-24 \mathrm{~h}$ after 60 min of $0 \mathrm{GD}$. $n=5$ observations per time point repeated with neurons from three different cultures. Lines indicate SEM. Statistical analysis was performed with one-way ANOVA with Tukey's correction. D, Representative Western blot analysis for synaptophysin (SYP), PSD-95, and GFAP expression in synaptoneurosomes prepared from WT neurons kept alone or in the presence of WT astrocytes.

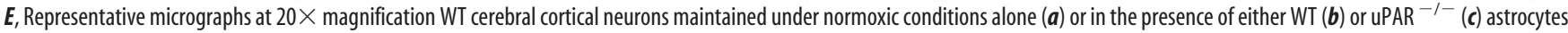
and immunostained with antibodies against PSD-95 (red) and bassoon (green). Bottom panels correspond to an electronic magnification of a representative neuronal extension for each experimental group. $\boldsymbol{F}$, Representative micrographs at $20 \times$ magnification of WT cerebral cortical neurons stained with anti-PSD-95 (red) and anti-bassoon ( $g r e e n)$ after 5 min of 0 GD and $24 \mathrm{~h}$ of recovery alone $(\boldsymbol{a})$ or in the presence of WT astrocytes either kept under normoxic conditions $(\boldsymbol{b})$ or previously activated by $3 \mathrm{~h}$ of $0 \mathrm{GD}(\boldsymbol{c})$. $\boldsymbol{d}$, WT neurons recovered in the presence of uPAR ${ }^{-1-}$ astrocytes previously exposed to $3 \mathrm{~h}$ of $0 G D$ conditions. Bottom panels correspond to an electronic magnification of a representative neuronal extension for each experimental group. $\mathbf{G}$, Mean percentage of synaptic contacts immunoreactive to both PSD-95 and bassoon in WT neurons exposed to the seven experimental conditions described in $\boldsymbol{E}$ and $\boldsymbol{F}$. Each observation was repeated 50 times in three different neuronal cultures. Statistical analysis was performed with one-way ANOVA with Tukey's correction. $\boldsymbol{H}$, Representative micrographs at $20 \times$ magnification of uPA ${ }^{-1-}$ cerebral cortical neurons stained with anti-PSD-95 (red) and anti-bassoon (green) antibodies under normoxic conditions ( $\boldsymbol{a}$ ) or $24 \mathrm{~h}$ after $5 \mathrm{~min}$ of $0 \mathrm{GD}$ and recovery alone ( $\boldsymbol{b}$ ) or in the presence of WT astrocytes previously activated by $3 \mathrm{~h}$ of $\mathrm{OGD}$ conditions (c). Bottom panels correspond to an electronic magnification of a representative neuronal extension for each experimental group. $I$, Mean percentage of synaptic contacts immunoreactive to both PSD-95 and bassoon in UPA ${ }^{-1-}$ neurons exposed to the experimental conditions described in $\boldsymbol{F}$. Each observation was repeated 35 times in three different neuronal cultures. Lines indicate SEM. Statistical analysis was performed with one-way ANOVA with Tukey's correction. $J$, Representative confocal microscopy images obtained within $1 \mathrm{~mm}$

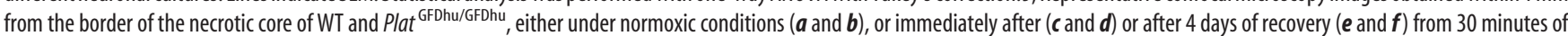
tMCA0. Baseline corresponds to micrographs obtained in a corresponding area of sham-operated animals. Images were taken at $60 \times$ magnifications and electronically enhanced 252 times. Red corresponds to PSD-95 and green denotes bassoon immunoreactivity. $\boldsymbol{K}$, Mean number of synaptic contacts per $2500 \mu \mathrm{m}^{2}$ of tissue in WT and Plat ${ }^{\text {GFDhu/GFDhu }}$ mice subjected to the experimental conditions described in $J . n=3$ animals per experimental group. Lines indicate SEM. Statistical analysis was performed with two-way ANOVA with Tukey's correction.

duce astrocytic activation; Fig. 2E,F), or after sham operation. Our data indicate that both strains of mice have comparable synaptic loss immediately after tMCAO $(88.24 \pm 3.2 \%$ and $70.28 \pm$ $4.25 \%$ in WT and Plau GFDhu/GFDhu mice, respectively; $n=3$ animals per group; $p=0.2$; two-way ANOVA. Fig. $6 J a-J d, K)$. In contrast, after $4 \mathrm{~d}$ of recovery, the number of synapses increased again in WT (recovery from $88.24 \pm 3.2 \%$ synaptic loss immediately after tMCAO to $59.07 \pm 6.27 \%$ after 24 h of recovery; $n=3$ animals per group; $p=0.001$; two-way ANOVA), but not in Plau ${ }^{\text {GFDhu/GFDhu }}$ mice (recovery from $70.28 \pm 4.25 \%$ synaptic loss immediately after tMCAO to $77.91 \pm 3.72 \%$ after $24 \mathrm{~h}$ of recovery; $n=3$ animals per group, $p=0.8$, two-way ANOVA. Fig. $6 J e, J f, K)$. These data indicate that binding of endogenous UPA to UPAR promotes synaptic recovery in the ischemic brain in vivo.

\section{Astrocytic TSP1 and synaptic LRP1 mediate} uPA/uPAR-induced synaptic recovery

Our studies indicate that uPA-uPAR binding induces astrocytic ERK1/2 activation and ERK1/2-mediated STAT3 phosphoryla- tion. Because STAT3 regulates the expression of astrocytic TSP1 (Tyzack et al., 2014) and because TSP1 promotes synaptogenesis (Christopherson et al., 2005), we decided to study the effect of uPA on astrocytic TSP1. Our data indicate that uPA induces the expression of astrocytic TSP1 (Fig. 7A, B) and that treatment with TSP1-blocking antibodies abrogates the synaptic recovery observed in WT neurons exposed to WT astrocytes previously activated by exposure to OGD conditions (Fig. 7C; $n=45$; $p<$ 0.0001, one-way ANOVA). Because LRP1 binds the N-terminal domain of TSP1 (Mikhailenko et al., 1997), we studied whether LRP1 mediates the protective synaptic effect of activated astrocytes. First, our immunoblottings with extracts from synaptoneurosomes prepared from the cerebral cortex of WT mice demonstrated that LRP1 is abundantly expressed in the synapse (data not shown). Then, we quantified the number of synapses in WT neurons recovered from 5 min of OGD in the presence of RAP, an inhibitor of LRP1 binding to its ligands (Strickland et al., 1990) and WT astrocytes previously activated by exposure to 
A

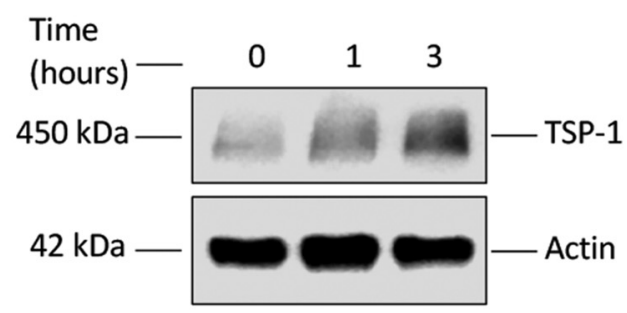

C

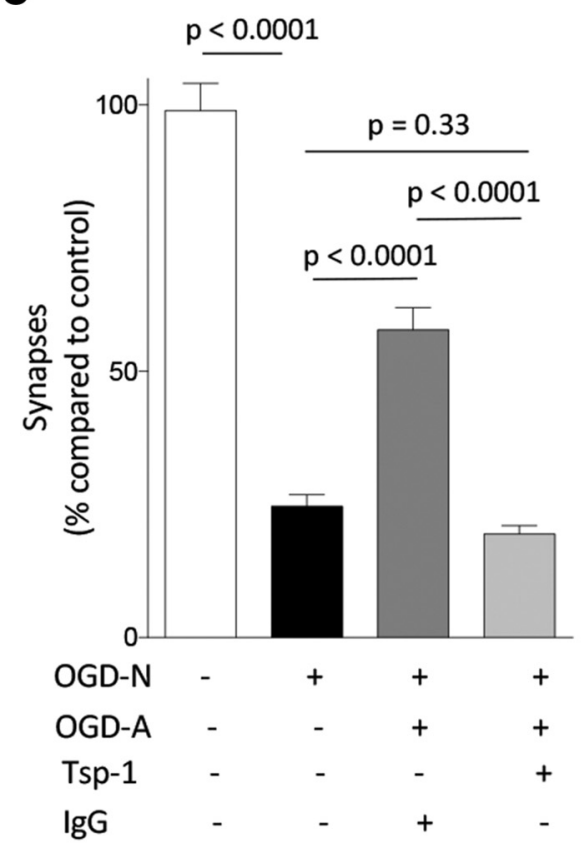

B

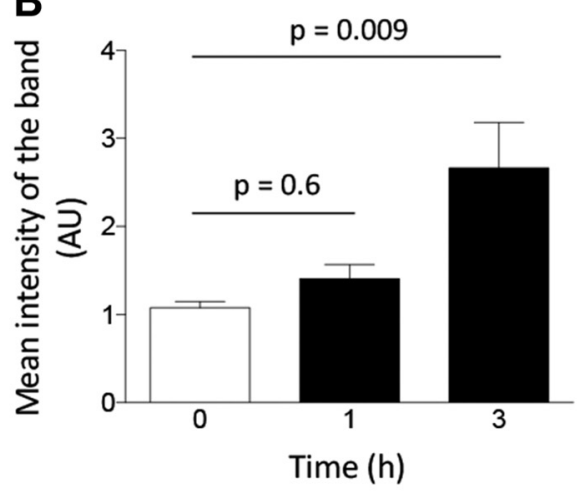

D

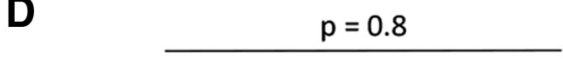

Figure 7. TSP1 and LRP1 mediate the effect of uPA on synaptic recovery. $\boldsymbol{A}, \boldsymbol{B}$, Representative Western blot analysis $(\boldsymbol{A})$ and mean intensity of the band $(\boldsymbol{B})$ of TSP1 expression in WT astrocytes incubated $0-3 \mathrm{~h}$ with $5 \mathrm{~nm} \mathrm{uPA} . n=3$ observations per experimental condition. Statistical analysis was performed with one-way ANOVA with Dunnett's correction. $C$, Mean percentage of synaptic contacts immunoreactive to both PSD-95 and bassoon in WT cerebral cortical neurons maintained under normoxic conditions (white bar; $n=45$ neurons examined) or exposed to 5 min of 0GD followed by $24 \mathrm{~h}$ of recovery alone (black bar; $n=30$ neurons examined) or in the presence of WT astrocytes previously exposed to $3 \mathrm{~h}$ of $0 \mathrm{GD}$ conditions and incubated with either an isotype lgG (control, dark gray bar; $n=25$ neurons examined) or $4 \mu \mathrm{g} / \mathrm{ml}$ TSP1-blocking antibodies (light gray bar; $n=46$ neurons examined). Lines indicate SEM. Each observation was repeated in three different neuronal cultures. Statistical analysis was performed with one-way ANOVA with Holm-Sidak correction. $\boldsymbol{D}$. Mean percentage of synaptic contacts immunoreactive to both PSD-95 and bassoon in WT cerebral cortical neurons maintained under normoxic conditions (white bar; $n=30$ cells examined) or exposed to 5 min of 0GD conditions followed by $24 \mathrm{~h}$ of recovery alone (black bar; $n=60$ cells examined) or in the presence of WT astrocytes previously exposed to $3 \mathrm{~h}$ of OGD conditions (dark gray bar; $n=55$ cells examined) or WT astrocytes exposed to $3 \mathrm{~h}$ of $0 \mathrm{GD}$ conditions in the presence of $125 \mathrm{~nm} \mathrm{RAP}$ (light gray bar; $n=26$ cells examined). A subset of neurons was incubated with RAP during $24 \mathrm{~h}$ under normoxic conditions (silver bar; 25 cells examined). Each observation was repeated in three different neuronal cultures. Lines indicate SEM. Statistical analysis was performed with one-way ANOVA with Holm-Sidak correction.

OGD conditions. Our data indicate that LRP1 antagonism abrogates synaptic recovery induced by exposure to activated astrocytes (Fig. $7 D ; n=26$ cells; $p=0.002$, one-way ANOVA).

\section{Discussion}

It has long been recognized that astrocytes can sense changes in neuronal activity (Bernardinelli et al., 2014) and that the release of astrocytic-derived soluble factors and the formation of a dense matrix of thin processes that enters in contact with the presynaptic and postsynaptic terminals allows them to have a direct effect on the synapse either by inducing the formation and stabilization of new synapses (Ullian et al., 2001; Slezak and Pfrieger, 2003; Hama et al., 2004) or by promoting their elimination via activation of intracellular cell signaling pathways (Chung et al., 2013). The studies presented here show that this cross talk between astrocytes and the synapse is pivotal, not only under physiological conditions such as development and neuronal plasticity, but also during the recovery phase from an acute ischemic injury. More specifically, our data indicate that, during the recovery phase from an ischemic injury, neurons release UPA and astrocytes recruit uPAR to their plasma membrane and binding of neuronal uPA to astrocytic uPAR mediates a cross talk between the different components of the tripartite synapse that leads to synaptic recovery in the ischemic brain. Importantly, despite the potential translational relevance of our findings, it remains to be elucidated by future studies whether diabetes, hypertension, and other risks factors for cerebrovascular disease have an effect on the synaptic reparative effect of uPA-uPAR binding.

The expression of $\mathrm{UPA}$ and $\mathrm{UPAR}$ in the CNS varies according to the developmental stage. Therefore, whereas, during the early 
phases of development, uPAR is found diffusely in the cell body and neurites of growing neurons, at later stages, it is detected only in distal axons and few growth cones (Merino et al., 2017). Likewise, whereas during development, uPA is found in large groups of neurons and oligodendrocytes (Sumi et al., 1992; Dent et al., 1993), at later stages, it is detected only in a circumscribed group of hippocampal neurons (Sappino et al., 1993). It has been demonstrated that stress and injury induce the expression of uPAR in different tissues (Smith and Marshall, 2010). Consistent with these observations, our earlier studies indicate that the expression of $\mathrm{UPA}$ and $\mathrm{UPAR}$ increases in the ischemic tissue during the recovery phase from an acute ischemic stroke (Wu et al., 2014) and that binding of uPA to uPAR promotes neurological recovery after the induction of experimental cerebral ischemia ( $\mathrm{Wu}$ et al., 2014; Merino et al., 2017). Together, these observations indicate that, in addition to catalyzing the conversion of plasminogen into plasmin on the cell surface, UPA and UPAR also promote neurorepair in the ischemic brain.

In contrast to neurons, the expression and function of astrocytic uPA/uPAR are less well characterized. Our work indicates that, under resting conditions, a large proportion of astrocytes exhibit UPAR immunoreactivity in their perinuclear zone and in limited areas of their plasma membrane, which is similar to other cell types (Grove et al., 2014). However, we found that this expression pattern changes during the recovery phase from a hypoxic injury, when UPAR is recruited to the astrocytic plasma membrane. These observations agree with studies reporting HIF1- $\alpha$-mediated increase in uPAR expression (Weidemann and Johnson, 2008) and the induction of the uPAR gene in reactive astrocytes after an ischemic injury (Zamanian et al., 2012).

Our studies show that hypoxia not only promotes the recruitment of uPAR to the astrocytic plasma membrane, but also induces morphological changes indicative of astrocytic activation. Based on these observations, we reasoned that there is a link between UPAR and hypoxia-induced astrocytic activation. This hypothesis was corroborated by our in vitro and in vivo data showing that hypoxia and cerebral ischemia activate WT but not $\mathrm{uPAR}^{-1-}$ astrocytes. More importantly, our results indicate that uPA is necessary and sufficient to induce astrocytic activation and that this effect does not require plasmin generation, but instead is mediated by activation of intracellular cell signaling pathways. Interestingly, our observation that neurons but not astrocytes release uPA during the recovery phase from an ischemic injury suggests a model in which the release of neuronal uPA leads to astrocytic activation around the injured synapse.

It has long been recognized that ERK1/2 activation is associated with excitotoxicity (Murray et al., 1998) and that its inhibition has a protective effect in the ischemic brain (Alessandrini et al., 1999). In contrast, our results indicate that ERK1/2 phosphorylation mediates uPA-induced astrocytic activation, which is required for synaptic recovery after an ischemic injury. These data suggest that, under excitotoxic conditions, ERK1/2 activation has opposite roles in neurons and astrocytes. Furthermore, our data show that ERK1/2-mediates uPA-induced STAT3 phosphorylation, which is known to be crucial for astrocytic activation and functional recovery after CNS injury (Herrmann et al., 2008). Together, these data indicate that ERK1/2 activation in astrocytes has a beneficial effect during excitotoxic conditions and that the ERK1/2-STAT3 pathway mediates UPA/uPARinduced astrocytic activation and synaptic recovery. More importantly, our work shows that uPA/uPAR binding leads to increase astrocytic expression of TSP1, a known STAT3-regu- lated astrocytic-secreted protein (Tyzack et al., 2014) that promotes CNS synaptogenesis (Christopherson et al., 2005).

The effect of astrocytic activation in the ischemic brain has been debated for a long time. Indeed, it has been proposed that reactive astrocytes inhibit axonal regeneration after CNS injury (Alilain et al., 2011) and produce inflammatory cytokines that exacerbate the harmful effects of the ischemic insult (Brambilla et al., 2005). In contrast, recent evidence indicates that reactive astrocytes are pivotal for withstanding the ischemic insult and promoting recovery after an ischemic stroke and that genetic deficiency of GFAP and vimentin has a harmful effect in the ischemic brain (Bush et al., 1999; Li et al., 2008). Consistent with these observations, our data show that uPA/uPARactivated astrocytes promote synaptic recovery in the ischemic brain and that this effect is mediated by astrocytic TSP 1 and synaptic LRP1.

Several mechanisms may explain the synaptic protection induced by uPA/uPAR-activated astrocytes. Activated astrocytes may either uptake glutamate from the synaptic cleft, decreasing its harmful excitotoxic concentrations (Danbolt, 2001); limit its spillover to extrasynaptic glutamate receptors (Kullmann and Asztely, 1998); provide energy to the injured neuron (Bernardinelli et al., 2014); decrease the probability of the synapse to disappear (Nishida and Okabe, 2007); or create new synaptic contacts (Verbich et al., 2012). In our model of synaptic recovery, neurons are placed in contact with astrocytes during the recovery phase, when the excitotoxic injury has already subsided. Moreover, uPA is released from neurons only $6-24 \mathrm{~h}$ after the acute hypoxic insult, when the concentrations of glutamate in the synaptic cleft have already returned to basal levels. Therefore, we postulate that the synaptic protective effect of TSP1 released by $\mathrm{uPA} / \mathrm{uPAR}$-activated astrocytes is not due to protection from the harmful effect of the acute excitotoxic injury, but instead is associated with either a protective effect of LRP1 on the synapse or the formation of new synaptic contacts. Further studies are needed to distinguish between these two alternatives.

In summary, based on the data presented here, we postulate a model in which, during the recovery phase from a hypoxic/ischemic injury, neurons release uPA and astrocytes upregulate and recruit uPAR to their plasma membrane. We propose that binding of neuronal uPA to astrocytic uPAR induces astrocytic activation around the injured synapse via ERK1/2-mediated STAT3 activation. We postulate that STAT3 activation leads to the release of astrocytic TSP1 and that the interaction between TSP1 and LRP1 in the synapse promotes synaptic recovery in neurons that have suffered an acute hypoxic injury. Together, these results indicate that uPA binding to uPAR mediates a cross talk between the injured synapse and neighboring astrocytes that promotes synaptic recovery in the ischemic brain.

\section{References}

Adams JC, Lawler J (2011) The thrombospondins. Cold Spring Harb Perspect Biol 3:a009712. CrossRef Medline

Alessandrini A, Namura S, Moskowitz MA, Bonventre JV (1999) MEK1 protein kinase inhibition protects against damage resulting from focal cerebral ischemia. Proc Natl Acad Sci U S A 96:12866-12869. CrossRef Medline

Alilain WJ, Horn KP, Hu H, Dick TE, Silver J (2011) Functional regeneration of respiratory pathways after spinal cord injury. Nature 475:196-200. CrossRef Medline

An JJ, Gharami K, Liao GY, Woo NH, Lau AG, Vanevski F, Torre ER, Jones KR, Feng Y, Lu B, Xu B (2008) Distinct role of long 3' UTR BDNF mRNA in spine morphology and synaptic plasticity in hippocampal neurons. Cell 134:175-187. CrossRef Medline 
Bernardinelli Y, Muller D, Nikonenko I (2014) Astrocyte-synapse structural plasticity. Neural Plast 2014:232105. CrossRef Medline

Brambilla R, Bracchi-Ricard V, Hu WH, Frydel B, Bramwell A, Karmally S, Green EJ, Bethea JR (2005) Inhibition of astroglial nuclear factor kap$\mathrm{paB}$ reduces inflammation and improves functional recovery after spinal cord injury. J Exp Med 202:145-156. CrossRef Medline

Bush TG, Puvanachandra N, Horner CH, Polito A, Ostenfeld T, Svendsen CN, Mucke L, Johnson MH, Sofroniew MV (1999) Leukocyte infiltration, neuronal degeneration, and neurite outgrowth after ablation of scarforming, reactive astrocytes in adult transgenic mice. Neuron 23:297-308. CrossRef Medline

Christopherson KS, Ullian EM, Stokes CC, Mullowney CE, Hell JW, Agah A, Lawler J, Mosher DF, Bornstein P, Barres BA (2005) Thrombospondins are astrocyte-secreted proteins that promote CNS synaptogenesis. Cell 120:421-433. CrossRef Medline

Chung WS, Clarke LE, Wang GX, Stafford BK, Sher A, Chakraborty C, Joung J, Foo LC, Thompson A, Chen C, Smith SJ, Barres BA (2013) Astrocytes mediate synapse elimination through MEGF10 and MERTK pathways. Nature 504:394-400. CrossRef Medline

Connolly BM, Choi EY, Gårdsvoll H, Bey AL, Currie BM, Chavakis T, Liu S, Molinolo A, Ploug M, Leppla SH, Bugge TH (2010) Selective abrogation of the uPA-uPAR interaction in vivo reveals a novel role in suppression of fibrin-associated inflammation. Blood 116:1593-1603. CrossRef Medline

Danbolt NC (2001) Glutamate uptake. Prog Neurobiol 65:1-105. CrossRef Medline

Dent MA, Sumi Y, Morris RJ, Seeley PJ (1993) Urokinase-type plasminogen activator expression by neurons and oligodendrocytes during process outgrowth in developing rat brain. Eur J Neurosci 5:633-647. CrossRef Medline

Echeverry R, Wu J, Haile WB, Guzman J, Yepes M (2010) Tissue-type plasminogen activator is a neuroprotectant in the mouse hippocampus. J Clin Invest 120:2194-2205. CrossRef Medline

Grove LM, Southern BD, Jin TH, White KE, Paruchuri S, Harel E, Wei Y, Rahaman SO, Gladson CL, Ding Q, Craik CS, Chapman HA, Olman MA (2014) Urokinase-type plasminogen activator receptor (uPAR) ligation induces a raft-localized integrin signaling switch that mediates the hypermotile phenotype of fibrotic fibroblasts. J Biol Chem 289:12791-12804. CrossRef Medline

Hama H, Hara C, Yamaguchi K, Miyawaki A (2004) PKC signaling mediates global enhancement of excitatory synaptogenesis in neurons triggered by local contact with astrocytes. Neuron 41:405-415. CrossRef Medline

Herrmann JE, Imura T, Song B, Qi J, Ao Y, Nguyen TK, Korsak RA, Takeda K, Akira S, Sofroniew MV (2008) STAT3 is a critical regulator of astrogliosis and scar formation after spinal cord injury. J Neurosci 28:7231-7243. CrossRef Medline

Herz J, Strickland DK (2001) LRP: a multifunctional scavenger and signaling receptor. J Clin Invest 108:779-784. CrossRef Medline

Hofmeijer J, van Putten MJ (2012) Ischemic cerebral damage: an appraisal of synaptic failure. Stroke 43:607-615. CrossRef Medline

Jiang Z, Zhang Y, Chen X, Lam PY, Yang H, Xu Q, Yu AC (2002) Activation of Erk1/2 and Akt in astrocytes under ischemia. Biochem Biophys Res Commun 294:726-733. CrossRef Medline

Jourdain P, Bergersen LH, Bhaukaurally K, Bezzi P, Santello M, Domercq M, Matute C, Tonello F, Gundersen V, Volterra A (2007) Glutamate exocytosis from astrocytes controls synaptic strength. Nat Neurosci 10:331339. CrossRef Medline

Kullmann DM, Asztely F (1998) Extrasynaptic glutamate spillover in the hippocampus: evidence and implications. Trends Neurosci 21:8-14. CrossRef Medline

Li L, et al. (2008) Protective role of reactive astrocytes in brain ischemia. J Cereb Blood Flow Metab 28:468-481. CrossRef Medline

Lijnen HR, Van Hoef B, Collen D (1987) Activation with plasmin of towchain urokinase-type plasminogen activator derived from single-chain urokinase-type plasminogen activator by treatment with thrombin. Eur J Biochem 169:359-364. CrossRef Medline

Liu Q, Trotter J, Zhang J, Peters MM, Cheng H, Bao J, Han X, Weeber EJ, Bu G (2010) Neuronal LRP1 knockout in adult mice leads to impaired brain lipid metabolism and progressive, age-dependent synapse loss and neurodegeneration. J Neurosci 30:17068-17078. CrossRef Medline

Merino P, Diaz A, Jeanneret V, Wu F, Torre E, Cheng L, Yepes M (2017) Urokinase-type plasminogen activator (uPA) binding to the uPA receptor
(UPAR) promotes axonal regeneration in the central nervous system. J Biol Chem 292:2741-2753. CrossRef Medline

Mikhailenko I, Krylov D, Argraves KM, Roberts DD, Liau G, Strickland DK (1997) Cellular internalization and degradation of thrombospondin-1 is mediated by the amino-terminal heparin binding domain (HBD): high affinity interaction of dimeric HBD with the low density lipoprotein receptor-related protein. J Biol Chem 272:6784-6791. CrossRef Medline

Murray B, Alessandrini A, Cole AJ, Yee AG, Furshpan EJ (1998) Inhibition of the p44/42 MAP kinase pathway protects hippocampal neurons in a cell-culture model of seizure activity. Proc Natl Acad Sci U S A 95:1197511980. CrossRef Medline

Nakajima C, Kulik A, Frotscher M, Herz J, Schäfer M, Bock HH, May P (2013) Low density lipoprotein receptor-related protein 1 (LRP1) modulates N-methyl-D-aspartate (NMDA) receptor-dependent intracellular signaling and NMDA-induced regulation of postsynaptic protein complexes. J Biol Chem 288:21909-21923. CrossRef Medline

Nishida H, Okabe S (2007) Direct astrocytic contacts regulate local maturation of dendritic spines. J Neurosci 27:331-340. CrossRef Medline

Oberheim NA, Goldman SA, Nedergaard M (2012) Heterogeneity of astrocytic form and function. Methods Mol Biol 814:23-45. CrossRef Medline

Panatier A, Vallée J, Haber M, Murai KK, Lacaille JC, Robitaille R (2011) Astrocytes are endogenous regulators of basal transmission at central synapses. Cell 146:785-798. CrossRef Medline

Paxinos G, Franklin KBJ (2001) The mouse brain in stereotaxic coordinates. San Diego: Academic.

Pekny M, Pekna M (2014) Astrocyte reactivity and reactive astrogliosis: costs and benefits. Physiol Rev 94:1077-1098. CrossRef Medline

Perea G, Navarrete M, Araque A (2009) Tripartite synapses: astrocytes process and control synaptic information. Trends Neurosci 32:421-431. CrossRef Medline

Rao A, Steward O (1991) Evidence that protein constituents of postsynaptic membrane specializations are locally synthesized: analysis of proteins synthesized within synaptosomes. J Neurosci 11:2881-2895. Medline

Resovi A, Pinessi D, Chiorino G, Taraboletti G (2014) Current understanding of the thrombospondin-1 interactome. Matrix Biol 37:83-91. CrossRef Medline

Sappino AP, Madani R, Huarte J, Belin D, Kiss JZ, Wohlwend A, Vassalli JD (1993) Extracellular proteolysis in the adult murine brain. J Clin Invest 92:679-685. CrossRef Medline

Silver J, Miller JH (2004) Regeneration beyond the glial scar. Nat Rev Neurosci 5:146-156. CrossRef Medline

Slezak M, Pfrieger FW (2003) New roles for astrocytes: regulation of CNS synaptogenesis. Trends Neurosci 26:531-535. CrossRef Medline

Smith HW, Marshall CJ (2010) Regulation of cell signalling by uPAR. Nat Rev Mol Cell Biol 11:23-36. CrossRef Medline

Strickland DK, Ashcom JD, Williams S, Burgess WH, Migliorini M, Argraves WS (1990) Sequence identity between the alpha 2-macroglobulin receptor and low density lipoprotein receptor-related protein suggests that this molecule is a multifunctional receptor. J Biol Chem 265:17401-17404. Medline

Sumi Y, Dent MA, Owen DE, Seeley PJ, Morris RJ (1992) The expression of tissue and urokinase-type plasminogen activators in neural development suggests different modes of proteolytic involvement in neuronal growth. Development 116:625-637. Medline

Tyzack GE, Sitnikov S, Barson D, Adams-Carr KL, Lau NK, Kwok JC, Zhao C, Franklin RJ, Karadottir RT, Fawcett JW, Lakatos A (2014) Astrocyte response to motor neuron injury promotes structural synaptic plasticity via STAT3-regulated TSP1 expression. Nat Commun 5:4294. CrossRef Medline

Ullian EM, Sapperstein SK, Christopherson KS, Barres BA (2001) Control of synapse number by glia. Science 291:657-661. CrossRef Medline

Verbich D, Prenosil GA, Chang PK, Murai KK, McKinney RA (2012) Glial glutamate transport modulates dendritic spine head protrusions in the hippocampus. Glia 60:1067-1077. CrossRef Medline

Wang X, Hasan O, Arzeno A, Benowitz LI, Cafferty WB, Strittmatter SM (2012) Axonal regeneration induced by blockade of glial inhibitors coupled with activation of intrinsic neuronal growth pathways. Exp Neurol 237:55-69. CrossRef Medline

Weidemann A, Johnson RS (2008) Biology of HIF-1alpha. Cell Death Differ 15:621-627. CrossRef Medline

Weingarten J, Lassek M, Mueller BF, Rohmer M, Lunger I, Baeumlisberger D, 
Dudek S, Gogesch P, Karas M, Volknandt W (2014) The proteome of the presynaptic active zone from mouse brain. Mol Cell Neurosci 59: 106-118. CrossRef Medline

Wilhelm BG, Mandad S, Truckenbrodt S, Kröhnert K, Schäfer C, Rammner B, Koo SJ, Claßen GA, Krauss M, Haucke V, Urlaub H, Rizzoli SO (2014) Composition of isolated synaptic boutons reveals the amounts of vesicle trafficking proteins. Science 344:1023-1028. CrossRef Medline

Wu F, Wu J, Nicholson AD, Echeverry R, Haile WB, Catano M, An J, Lee AK, Duong D, Dammer EB, Seyfried NT, Tong FC, Votaw JR, Medcalf RL, Yepes M (2012) Tissue-type plasminogen activator regulates the neuronal uptake of glucose in the ischemic brain. J Neurosci 32:9848-9858. CrossRef Medline

Wu F, Catano M, Echeverry R, Torre E, Haile WB, An J, Chen C, Cheng L, Nicholson A, Tong FC, Park J, Yepes M (2014) Urokinase-type plasmin- ogen activator promotes dendritic spine recovery and improves neurological outcome following ischemic stroke. J Neurosci 34:14219-14232. CrossRef Medline

Yang Z, Wang KK (2015) Glial fibrillary acidic protein: from intermediate filament assembly and gliosis to neurobiomarker. Trends Neurosci 38: 364-374. CrossRef Medline

Yoon SY, Lee YJ, Seo JH, Sung HJ, Park KH, Choi IK, Kim SJ, Oh SC, Choi CW, Kim BS, Shin SW, Kim YH, Kim JS (2006) uPAR expression under hypoxic conditions depends on iNOS modulated ERK phosphorylation in the MDA-MB-231 breast carcinoma cell line. Cell Res 16:75-81. CrossRef Medline

Zamanian JL, Xu L, Foo LC, Nouri N, Zhou L, Giffard RG, Barres BA (2012) Genomic analysis of reactive astrogliosis. J Neurosci 32:6391-6410. CrossRef Medline 